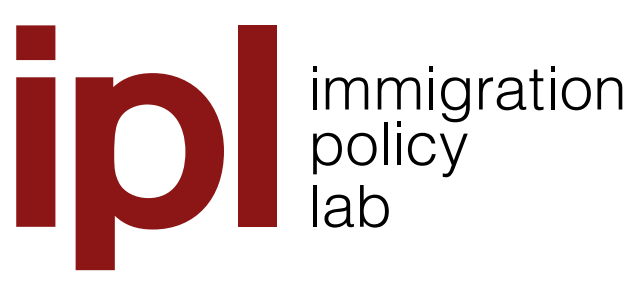

Working Paper Series

Working Paper No. 21-01

How Exile Shapes Online Opposition: Evidence from Venezuela

Jane Esberg and Alexandra Siegel 


\title{
How Exile Shapes Online Opposition: Evidence from Venezuela
}

\author{
Jane Esberg* \\ Alexandra Siegel ${ }^{\dagger \ddagger}$
}

March 8, 2022

\begin{abstract}
How does exile affect online dissent? By internationalizing activists' networks and removing them from day-to-day life under the regime, we argue that exile fundamentally alters activists' political opportunities and strategic behavior. We test the effect of exile on activists' public discourse in the case of Venezuela, through an analysis of over 5 million tweets by 357 activists spanning seven years. Our results suggest that after going into exile activists increasingly emphasize foreign-led interventions to shape their home country politics; focus relatively less on local grievances; and become more harshly critical of the regime. This is partly due to the changes in exiles' networks: after leaving, activists increase their interactions with foreign actors and tweet more in English. This work contributes to our understanding of the relationship between exile - one of the most ubiquitous yet understudied forms of repression - and dissent in the digital age.
\end{abstract}

${ }^{*}$ Postdoctoral Fellow, Princeton's Empirical Studies of Conflict Program and the International Crisis Group. jesberg@crisisgroup.org

${ }^{\dagger}$ Assistant Professor, University of Colorado Boulder.

${ }^{\ddagger}$ For helpful feedback, we would like to thank Ivan Briscoe, Tarek Ghani, Phil Gunson, Dorothy Kronick, Renata Segura, Lauren Young, Stanford's Immigration Policy Lab, UCLA's Politics of Order and Development Lab, and members of the WUSTL Methods Lab. Emma Li, Beatriz Teles, Emily Schultis, and Emily Tomz provided excellent research assistance. 
Exile is an emotionally devastating experience, that's well recognized. What not everyone grasps is that it's also a politically transformative one.

Francisco Toro, "My Name is Francisco, and I Am a Toxic Exile," Caracas Chronicles

Exile - the banishment of dissidents from their home country ${ }^{1}$ — is among the most common forms of repression targeting political opponents. Used by regimes to stifle opposition, its goal is to limit the influence of activists by splintering their networks and reducing their domestic influence (Esberg 2020). However, exiles typically continue their activism overseas. Activists from across the globe have used a variety of strategies to shape foreign policies and alter outcomes in their home countries. ${ }^{2}$ The rise of digital media technologies has afforded exiled dissidents new platforms to disseminate messages, enabling them to amass large online followings and to produce content in multiple languages targeting diverse audiences (Michaelsen 2018; Kendzior 2012). While exile is a tried and true strategy for authoritarian and hybrid regimes seeking to stifle domestic opposition, we know relatively little about its effects, especially since the advent of social media (Brinkerhoff 2009).

In this article, we ask how exile affects elite online dissent. By forcing opponents from the country, exile internationalizes elites' networks, strengthening their relationships with foreign audiences and opening new opportunities for international activism (Adamson and Demetriou 2007; Brinkerhoff 2016; Koinova 2021). It also removes them from day-to-day life in their home countries, making them less vulnerable to repression, but also less directly connected to their domestic constituencies (Henry and Plantan 2021; McKeever 2020). Because of this, we argue that exile should fundamentally change activists' strategies, including the types of policies and issues that they discuss publicly.

More specifically, we expect exile to change the content of activists' dissent in three central

1. Exile is a difficult to define term, theoretically because there is no universally agreed upon definition, and empirically because it can be difficult to gauge the reason that dissidents leave their country. While exile is sometimes defined quite broadly as "political dislocation" (Sanchez and Blumenthal 2022), or used to refer to mass emigration from authoritarian regimes (Wright and Zuñiga 2007), it is typically not a legally defined punishment. Here, we adopt Moss (2021) definition of exile as "the direct and indirect banishment of dissidents (or suspected dissidents) from the home country, including when the threat of harm and imprisonment prevents activists from returning" (72). Our concept of exile is closely linked to the "diaspora entrepreneurs" discussed in Koinova (2021) and Brinkerhoff (2016). However, we narrow in on opposition figures who were politically active both before and after joining the diaspora, and who faced threat of repression in the home country.

2. A large body of literature has examined diaspora activism abroad in diverse contexts including Shain (1988, 1994, 2002), Adamson and Demetriou (2007), Adamson (2013), Koinova and Karabegović (2019), Koinova (2014, 2011), Moss (2021), Girard and Grenier (2008), and Moss (2021). 
ways. First, we expect exile to increase activists' support for foreign-led policy solutions. Going abroad means that exiles are socialized into new communities, and have very different methods of activism available to them. For example, exiles may be particularly well-placed to lobby their host country governments, but are less capable than in-country activists of participating in domestic political processes (Brinkerhoff 2011, 2016; Koinova 2021; Henry and Plantan 2021). As exiles' networks become more international, it follows that the types of policies that they discuss and advocate for publicly should change, to highlight and take advantage of the tools that are most readily available to them.

Second, we expect activists to focus less on local grievances. With more international networks, exiles have incentives focus on topics that resonate with a broad audience. Moreover, with less connection to on-the-ground events at home, exiles may have less knowledge of or involvement in matters of primarily domestic interest (McKeever 2020). As a result, we expect exiles' rhetoric to shift away from local issues. Finally, we theorize that harsh criticisms of the home country government should increase following exile. Bold, national-level critiques should resonate with a broader and more international audience. Activists may also be less likely to self-censor due to reduced fears of repression abroad, particularly where home-country regimes have low state capacity for transnational repression (Shen and Truex 2021).

We test this theory in the case of Venezuela, where many opponents of Nicólas Maduro have gone into exile. To do this, we developed a dataset of online opposition speech. Drawing on lists of politicians and other opposition activists, we ascertained their exile status and collected their Twitter handles. We then gathered the full tweet history for the 357 activists in our sample dating back to January 2013, of whom 94 were exiled, totaling more than 5 million social media posts. Because Venezuela has one of the highest rates of Twitter penetration in the world (Silver et al. 2019), and the platform is widely used to discuss politics (Munger et al. 2019; Waisbord and Amado 2017; Morales 2020; Morselli, Passini, and McGarty 2021), Twitter data enables us to develop temporally granular measures of how exiled and non-exiled activists express dissent online.

Using text analysis and a two-way fixed effects design, we demonstrate that Venezuelan activists' discourse changes after exile. After leaving the country, opposition figures become more likely to discuss and support popular foreign-led solutions to Venezuela's political and economic crisis, including diplomacy, foreign intervention, and sanctions. By contrast, activists in exile are somewhat less likely to discuss local grievances, like food shortages 
and blackouts, as well as local protests. Exile is also associated with more openly harsh anti-regime criticisms, such as accusations of narco-trafficking, fascism, Cuban or Russian invasion, and extrajudicial repression.

Exploring the mechanism by which exile might influence online dissent, our analysis suggests that after leaving Venezuela activists' online networks become more international and focused on foreign actors. We demonstrate that discussions of foreign entities increase after exile; the percent of tweets directed at international actors rises; and tweets in English become more common. We also demonstrate that references to the new host country particularly increase, providing further evidence that this internationalization is largely the result of new overseas networks.

By empirically demonstrating how exile affects activists' online discourse, this work builds on a growing body of research examining the relationship between repression and dissent in the digital age (Pan and Siegel 2020; Roberts 2018; King, Pan, and Roberts 2013; Woolley and Howard 2018). Our focus on elite opposition figures also provides novel evidence to the literature on diaspora activism abroad (Adamson and Demetriou 2007; Adamson 2013; Koinova and Karabegović 2019; Koinova 2014, 2011; Moss 2021; Girard and Grenier 2008).

More broadly, our findings offer new evidence of the political consequences of exile - one of the most ubiquitous but least studied forms of repression. Research on the individual-level consequences of dissent typically focuses on the effects of violent repression, like imprisonment or killings (Bautista 2015; García-Ponce and Pasquale 2015; Young 2019, 2020). While exile is similarly used to undermine opposition, exiled communities are often actively engaged in agenda-setting overseas (Danitz and Strobel 1999; Girard and Grenier 2008). Our research shows how exile not only changes the geography of opposition movements, but the content of activists' public dissent, in line with literature on how migration can shape political beliefs and tactics (Batista, Seither, and Vicente 2019; Careja and Emmenegger 2012; Pérez-Armendáriz and Crow 2009).

\section{The Effect of Exile on Political Discourse}

The goal of exile under repressive regimes is to fragment the opposition, scattering activists across countries to reduce the effectiveness of anti-regime mobilization (Esberg 2020; Wright and Zuñiga 2007). By casting opponents out of the country, traditional opposition networks are broken, and exiles no longer have direct access to the country's citizens and institutions. Research on the individual-level effects of repression has found that proximity to violence 
often dampens political participation, which may make dissent less likely (Bautista 2015; García-Ponce and Pasquale 2015; Rozenas and Zhukov 2013; Young 2020). This contributes to a broader literature on the dynamic relationship between repression and dissent (Carey 2006, 2009; Christensen 2018; Davenport and Moore 2012; Siegel 2011; Truex 2018). However, much of this work focuses on overtly violent repression, like imprisonment and killings.

Exile is markedly different from many other forms of repression in that exiles can continue their activism abroad. Literature on diaspora politics more broadly shows how activists from diverse home countries including Albania, Armenia, Bosnia, China, Chile, Cuba, Democratic Republic of Congo, Kosovo, Palestine, Libya, Russia, South Africa, Syria, Tibet, and Yemen have used brokerage, framing, ethnic outbidding, lobbying, coalition-building, and the diffusion of ideas to shape foreign policies and alter outcomes in their home countries (Shain 1988, 1994, 2002; Adamson and Demetriou 2007; Adamson 2013; Koinova and Karabegović 2019; Koinova 2014, 2011; Moss 2021; Girard and Grenier 2008). Indeed Shain (1999) described political exiles as "some of the most prominent harbingers of regime change in the world." Social media has also transformed the tools available to exiles, giving opposition figures a platform to communicate publicly with other activists, international audiences, domestic citizens, and the regime itself (Michaelsen 2018; Kendzior 2012; Brinkerhoff 2016).

We expect that exiles' behavior abroad will be shaped by their changing political opportunities and constraints in their new host countries (Wayland 2004; Koinova 2014). We draw on the literature on transnational social movements, though we focus in on an important subset of the broader diaspora and "diaspora entrepreneurs": elite exiles who began their political work in the home country, under a repressive regime, and fled due to fear of harm related to their activism (Moss 2021). We expect opposition elites, including those in exile, to be strategic actors who will adjust their activism to best achieve their goals. Given the widespread use of exile to suppress opposition, understanding how it changes the content of dissent is particularly important. We argue that exile changes dissidents' political opportunity structures by internationalizing their networks and creating distance from the repressive regime.

First, moving abroad enables exiles to develop new relationships and audiences both among the broader diaspora and with foreign governments, civil society actors, and journalists (Adamson and Demetriou 2007; Brinkerhoff 2016). This "institutional acculturation" offers dissidents new opportunities for influence, or vertical voice (Hirschman 1978; Brinkerhoff 2011; Henry and Plantan 2021). With access to new international audiences and the ability 
to lobby their host country governments, exiles acquire a new toolkit for opposition. And as political actors, exiles should be strategically responsive to these opportunities. It follows that after moving abroad, activists should shift both their modes of activism and the content of their dissent to match their new circumstances.

At the same time, exiles' links to the home community may weaken, particularly under conditions of harsh repression and censorship. As McKeever (2020) describes, "from their sanctuary, activists find they retain limited access to the closed political opportunity structure of their sending country but are offered a range of opportunities by their new host country." Exiles are not able to engage in the forms of dissent that they may have done domestically, such as organizing marches against the regime or participating in formal political processes. Particularly without the ability to visit in person, their connections to local politics and constituencies may weaken, making them less engaged with on-the-ground events - even with digital technologies available (Henry and Plantan 2021; Hussain and Howard 2013; Karimzad and Catedral 2018; Kuran 1991; Pierskalla 2010). By leaving the country, their relative advantage in activism shifts to serving as "bridge figures" (Zuckerman 2013) between the host and home country, broadcasting messages to an international audience and brokering between previously unconnected actors and entities inside and outside of the home country (Andén-Papadopoulos and Pantti 2013; Shain 1999; Koinova 2021; Moss 2021).

Finally, going abroad reduces' activists' fear of repression and reprisals from their home country governments. While moving abroad does not free opposition figures from threats to their own safety or livelihoods - or those of their family members - they face fewer risks abroad than they do at home. Though transnational repression is on the rise globally, and has been shown to have chilling effects on diaspora activism in diverse contexts (Moss 2021; Adamson 2020; Tsourapas 2021; Adamson and Tsourapas 2020; Dalmasso et al. 2018), exiles should nevertheless be less vulnerable than at home. This should be especially true for dissidents from host states with low state capacity for transnational repression. Well-known exiled elites who began their activism under repressive governments may also be less vulnerable to the dampening effects of repression.

We focus on the online behavior of activists. Political actors are increasingly taking to Twitter to communicate policy platforms and criticize regimes that otherwise may limit freedom of speech (Pan and Siegel 2020). Unlike statements through organizations or to the press, communication on social media is direct and frequent, giving us a rich source of fine-grained data that reflects activists' priorities, policy positions, and communication strategies. While 
social media data does not necessarily allow us to assess whether true or sincere attitudes towards the regime change with exile, we can estimate how the content of activists' strategic public discourse shifts. This, in turn, can tell us about how dissent changes with leaving the country, differentiating the approaches of activists forced out and those who remain.

We expect to see three central changes to activists' online discourse after exile. First, exiles should increasingly promote and discuss foreign-led solutions to problems in the home country, in response to the new networks and new opportunities afforded them (Koinova 2021). The exact nature of these solutions should reflect the foreign policy goals, ideology, and values of the host country government, as well as the ideology of the exiles themselves (Shain 1999). For example, Cuban exiles' calls for harsh sanctions have dovetailed with the US government's historically anti-leftist policies in Latin America (Falke 2000). Similarly, Iraqi exiles' calls to remove Saddam Hussein from power in the early 2000s aligned with hawkish US foreign policy goals dating back to the first Gulf War (Vanderbush 2009). Other diaspora communities have sought much more limited goals: Belarusian activists have used their position as pro-democracy advocates abroad to draw attention to repression at home and to lobby European governments to expand sanctions and cut ties with state-owned companies (Rudnik 2021).

Second, exiles should focus less on local domestic grievances and activism, both in response to their new position as brokers between the host and home country, and because their knowledge of certain aspects of local politics may be less relevant (McKeever 2020; Yeh 2007). While we expect this to be true even as online tools facilitate transnational connections (Karimzad and Catedral 2018), the extent may vary based on exiles' perceived likelihood of return as well as the degree of censorship in their home country. For example, China heavily censors discussions of collective action, though allows for the expression of grievances more generally (King, Pan, and Roberts 2013). If discussions of local collective action are censored at home, we might observe an increase in such discussions as activists have the opportunity to comment on such issues for the first time. Alternatively, exiles from countries with strong censorship structures like China may experience even greater levels of disconnection with their home-country networks (King, Pan, and Roberts 2013).

Third, activists may phrase their criticisms in harsher terms, both strategically - to appeal to their growing international networks - and due to reduced self-censorship. We expect these effects to be moderated by state capacity for transnational repression, since fears of being targeted abroad may reduce exiles' willingness to speak out (Adamson 2020; Tsourapas 2021; 
Adamson and Tsourapas 2020; Dalmasso et al. 2018; Moss 2021). Such fear may moderate the effects we find, though concerns about international reach should be less intense for elite exiles, who are already vulnerable due to their history of open dissent in the home country.

While the specific ways in which the content of dissent changes may vary by home and host country context, we expect our broad theory to hold for exiles coming from repressive regimes and seeking structural change in the home country. In these contexts, the goal of opposition activism both internally and internationally is national-level political reform, through methods like regime change and negotiated settlement. In such cases foreign pressure may be particularly impactful; local grievances may be of less direct salience to the political conflict; and there is a clear subject of criticism. Such exiles differ substantially from refugees fleeing generalized conflict, where first-order goals may revolve around reducing violence. They should also differ from exiles from ethnic groups and separatist regions, who typically seek more limited territorial and administrative goals revolving around self-determination. Nevertheless, this study should cover a variety of authoritarian and hybrid regimes that use repression to suppress opposition.

\section{The Case of Venezuela}

We test this theory in the case of Venezuela, where the increasingly authoritarian president Nicolás Maduro has often pushed opposition out of the country as a tool of control. Maduro first took power upon the death of his predecessor, Hugo Chávez, in March 2013. Since then, he has taken a number of measures to ensure greater control over the electoral system, in an attempt to further disempower the opposition. Among others, these include barring prominent members of the opposition from running for office; vote buying, including by strategically doling out food aid and medical care; and packing the national electoral board and court system with loyalists (Rodrigues de Caires and Sánchez Azuaje 2018; Mainwaring and Pérez Liñán 2015; Faiola 2018; International Crisis Group 2020; Casey 2019). In response to electoral irregularities in the May 2018 elections, Juan Guaidó - a member of the National Assembly and a central figure of the opposition - declared himself acting president. The United States quickly recognized him, and dozens of other countries followed (though many, including the European Union, have since downgraded his status). Massive protests, as well as an abortive military uprising, occurred in the months after.

Simultaneously, Venezuela has suffered one of the most severe economic crises in decades. Inflation and the national debt exploded; poverty, fuel shortages, and hunger began to rise. Though initially buoyed by the price of oil, plunging prices reduced the government's ability 
to spend on social programs to keep the political base intact (Davies 2016). ${ }^{3}$ One in three Venezuelans is food insecure (World Food Program 2020), and estimates suggest an 85\% shortage in medicine, leading to a resurgence of treatable diseases (EFE 2017; Faiola and Krygier 2018). Four in ten households experience daily electricity outages (The Guardian 2020).

In this period of political and economic crisis, repressive actions against political opponents have intensified. The security services regularly respond to peaceful protests with beatings, tear gas, and close-range rubber bullets. Political opponents are imprisoned or barred from running for political office. Estimates suggest thousands of Venezuelans are now killed per year in extra-judicial murders (UNCHR 2019). For example, under the pretext of addressing terrorism, "Operation Peoples' Liberation" (OLP) led to more than 500 murders by the security services, as well as evictions, home raids, and detentions (Human Rights Watch 2019).

\section{Online Political Discourse in Venezuela}

Venezuela has a high rate of social media penetration, with $69 \%$ of adults using at least one social media app (Silver et al. 2019). As of 2019, 21\% of Venezuelans use Twitter, compared to $22 \%$ of U.S. citizens as a point of reference. Twitter has long been a popular platform for discussing politics in Venezuela. Indeed, Chávez was considered the second most influential leader in the world on Twitter (Morales et al. 2015). Twitter has also been heavily used by opposition activists and politicians in Venezuela, as in other parts of Latin America (Munger et al. 2019; Calvo 2015; Lupu, Ramírez Bustamante, and Zechmeister 2020; Waisbord and Amado 2017; Morales 2020; Morselli, Passini, and McGarty 2021). Government control over the media has increased under Maduro, with most news sources being state-run and even independent outlets heavily restricted (Nugent 2019). One blogger wrote in 2014: "No longer will we just settle on trusting that Globovisión will carry whatever little things we do. We will now have to explore the use of other outlets - Twitter, Capriles.tv, Facebook" (Friedman 2019).

As a result, Twitter plays an important role in the political media landscape in Venezuela more broadly. As one political figure in exile notes: "Twitter phenomena... try to condition, often with success, local politics" (International Crisis Group 2021). Media produced abroad tends to get picked up in the local press and discourse, precisely because of limits on free speech domestically: "Exiles like those in Miami have a great deal of influence because

3. For more on the history of this practice, see Dunning (2010) and Gulotty and Kronick (2020). 
of media capacity" (International Crisis Group 2021). A 2014 survey found that $74 \%$ of Venezuelans learned about politicians' political beliefs on Twitter, the most of any country polled (Friedman 2019).

\section{Exile and Online Discourse in Venezuela}

Maduro's opponents are frequently forced into exile. ${ }^{4}$ While we lack statistics on repression in the country, nearly four million Venezuelans, about $13 \%$ of the population, have left since 1999 (UNHCR 2019). This exodus is largely due to the economic and humanitarian crisis, but many activists were also pushed out of the country (WLRN 2017). Political exiles in Venezuela often remain active in politics in their host country; for example, the Organization of the Venezuelan Politically Persecuted in Exile (VEPPEX) frequently advocates for aggressive U.S. policies targeting Maduro. ${ }^{5}$

Exiles themselves view the experience of leaving Venezuela as fundamentally altering how they approach the regime. One formerly exiled activist puts it in the following way: "It's like cream and milk. When cream forms, it doesn't look different from milk, but it's not milk, you know? The same happens with the radicalization of the diaspora. [After exile] you're the cream, not the milk within Venezuela." ${ }^{\prime 6}$ Describes Toro (2020), "the day politics forces you out of your home, a wedge is driven between you and the country you leave behind."

The theory presented above outlines the general patterns we expect to see when exiles leave a repressive regime, conditional on our scope conditions. However, the specific ways that these relationships play out we expect to vary, based on factors like the feasibility of different policy options and the threat of repression both at home and abroad (Brinkerhoff 2016; Koinova 2021). We thus adapt our theory to identify three testable hypotheses for the case of Venezuela, based on the particularities of the context.

Our theory first predicts that exile should be associated with an increased discussion of foreign-led solutions to the Venezuelan crisis. Given that we expect exiles to advocate for policies that may appeal to their host country governments and are widely viewed as possible, we focus on the three most common proposed policy solutions in this period: military intervention, sanctions, and diplomacy. While it has not been pursued, hardline opponents and

4. While Maduro lacks the legal authority to officially exile opponents, he has forced them to flee through threats of detention or harassment, and occasionally barred opponents from reentering the country after trips abroad.

5. See https://www.veppex.com/.

6. Phone interview quote provided by the International Crisis Group, September 2020. 
international officials regularly discuss humanitarian or military intervention in Venezuela. Guaidó himself has said on international military action, "If it's necessary, maybe we will approve it" (Faiola 2019). Others have proposed forceful humanitarian intervention to deliver aid (UN 2019). Since 2014 a number of countries - including the U.S., Canada, and Mexico - have placed sanctions against individuals and companies associated with Maduro, targeting sectors from mining to food (Service 2020). Diplomacy by international actors has also been a popular solution to ease the political crisis in Venezuela, in recognition of the country's importance to broader geopolitics. To that end, Norway facilitated a series of talks that made some headway towards an easing of conflict (International Crisis Group 2022).

Second, our theory suggests that exile will be associated with less discussion of local grievances or mobilization efforts. For Venezuela, which is in the midst of multiple humanitarian and economic crises, we expect this to be most visible in discussions of devastating internal grievances related to issues like electricity blackouts; water and food shortages; and the struggling medical system. Despite the severity of this crisis, we expect that discussions of these shortages - particularly those describing local circumstances - will decrease: exiles are no longer affected by such shortages, they may lack details on when they are occurring, and such criticisms may be less relevant to international audiences. With regard to collective action events, Eubank and Kronick (2021) have shown that domestic networks in Venezuela are a major determinant in protest mobilization. While there have been a number of very significant national protest movements, collective action events also take place at a smaller scale. One estimate suggests there have been as many as 50,000 protests in Venezuela since Maduro's election (El Tiempo 2019). While we expect exiles to offer support for such protests, particularly during major national events, exiles are no longer able to participate directly. For that reason we expect them to be less engaged in organizing events and less likely to discuss more local protest activities.

Third, we expect that the nature of criticisms targeting the regime will change, becoming increasingly harsh. Criticisms of the Maduro government are highly varied, but we focus on several categories that we consider particularly severe. First, the Maduro government is often tied to narco-trafficking, linked to the alleged Cartel de los Soles run by high-ranking members of the government (Rashbaum, Weiser, and Benner 2020). Second, because of his attempts to subvert checks and balances on his power, Maduro is frequently accused of fascism. Third, critics attack the "hijacking" or "invasion" of Venezuela by Russian and Cuban agents supporting the current regime (Borges 2019). Fourth, as described Maduro frequently uses extrajudicial methods of repression to silence opponents. These criticisms 
are largely, if not entirely, based in truth, particularly given Maduro's widespread human rights violations. We argue, however, that they represent broad, severe, and national-level attacks on the regime, both more interpretable by international audiences and reflective of exiles' greater outspokenness.

We also expect to find evidence for one key mechanism behind our theory: the internationalization of activists' networks. With socialization into new communities and changing opportunities for influence, we expect activists to increasingly use rhetoric targeted towards international audiences. A core component of our theory posits that activists will increasingly interact with and appeal to international actors after exile. Interaction with citizens of host countries should be particularly likely to increase, since these individuals should be the primary target of activism. For example, Venezuelan opposition leaders living in Miami should be more focused on U.S. action against Venezuela than those living in Bogotá.

\section{Data and Methods}

To understand the relationship between exile and online political discourse, we draw on original data on the exile of Venezuelan opposition activists. We collected more than 5 million tweets posted by opposition leaders since $2013 .{ }^{7}$ We then estimate the impact of exile on different topics of interest - foreign policy, domestic grievances, and harsh criticism of the regime - using difference-in-differences (DID) models and event study analyses. We describe our data and methods in greater detail below.

\section{Data}

\section{Venezuelan Opposition}

To explore the relationship between exile and discourse on Twitter, we first identified wellknown Venezuelan opposition activists. We included all opposition deputies who served on Venezuela's National Assembly (established in 2000), which is the most influential governing

7. We chose to use Twitter data, rather than social media data from other platforms, for both substantive and methodological reasons. First, Venezuela has one of the highest rates of Twitter penetration in the world (Silver et al. 2019), and the platform is widely used to discuss politics and has been heavily used by opposition activists and politicians in Venezuela (Munger et al. 2019). Methodologically, Twitter data enables us to move beyond just the content of social media posts produced by opposition activists to examine network structure. Specifically, we can examine what types of users the opposition actors in our study interact with over time, enabling us to test key mechanisms that we would not be able to evaluate empirically using data from other popular platforms like Facebook or Instagram. 
body on which opponents serve; opposition mayors elected in the last two cycles, since $2013^{8}$; and prominent unelected activists and journalists who are publicly recognized as regime opponents. Since the latter we identified through searches of public news sources, we show in Appendix B that results hold using the more regularized sample of elected politicians. We coded each individual for whether they were in exile, the date they left Venezuela, and their destination internationally. Where date of exile could not be precisely determined, we used the date of the first news article listing the individual as living in exile.

Since our focus is on how exile impacts online political discourse, we then collected activist Twitter handles, excluding those who did not have an account or who have not tweeted since 2013. This left us with a sample of 357 opposition leaders who were active on Twitter as of May 2020, of whom 94 were exiled. ${ }^{9}$ The majority of those exiled (86) left after Maduro took office in 2013. Though after our data collection ended Maduro granted pardons to a number of opposition members living in exile, in our sample just two activists returned to Venezuela. ${ }^{10}$

Exile is difficult to measure and it is often applied to a wide range of reasons for individuals fleeing their home countries. For example, estimates for Chilean exiles during Augusto Pinochet's dictatorship range from several thousand to 200,000, the latter including those who fled not because of direct pressure but due to political and economic concerns (Esberg 2020). Though most of the Venezuelan exodus fled due to economic collapse, they are still often referred to as Venezuelans "in exile." Recognizing the difficulty of operationalizing exile, we adopt a broad, neutral measure: we include any activist in our dataset who had left Venezuela at the time of data collection. In practice, however, this decision is rarely voluntary. Many exiles are forced out through harassment, such as threats of detention, but pushing them abroad may have been what the regime intended (Wright and Zuñiga 2007). For example, Guaidó was threatened with charges during a brief period outside the country in 2019, but those threats seemed designed to force him into exile; he has not yet been charged, and remains in the country. Among the exiled whose reason for leaving the country we could identify, 44 preemptively fled detention, violence, threats, or prosecution; 33 were

8. We include the widest possible set of National Assembly deputies because they tend to be nationally prominent and remain politically active even after leaving the legislatures; mayors are typically earlier in their political careers. Given realignment in parties and positions over time, particularly before and after Chávez's death, we include a wide set of opposition or non-aligned parties but exclude politicians who have expressed support for Maduro.

9. An additional 16 activists did not have Twitter accounts. The high rate of matching to handles is a reflection of how widespread the use of Twitter is among Venezuela elites.

10. We do not count exile that lasted less than a month, including Guaidó's own 10-day exile. 
forced out by the regime through unspecified measures; 6 fled for political reasons; and three were barred from reentering after going abroad. Just three identified as being in voluntary or self-imposed exile.

Our sample is not exhaustive, and our results can best be interpreted as how exile impacts the online discourse of opposition elites. Because we collected our list of opponents through internet searches, we likely missed many activists operating locally outside of major cities. This also means our sample may bias towards wealthier elites, which likely impacts their ability to leave the country and the host countries where they settle. ${ }^{11}$ We also cannot know the degree to which our sample is representative of the broader diaspora, though we expect political actors to be particularly strategic in shifting their online discourse to reflect their new positioning. However, this population of political elites are of great interest to the regime and to the international community, since these more prominent national-level political figures are the most visible outside the country.

\section{Twitter Data Collection}

Once we had identified our sample of 357 opposition leaders who had active Twitter accounts, we used Twitter's Historical Power Track API to collect their tweets from January 1, 2013 until May 31, 2020, when we began collecting data. This API provides access to the entire historical archive of public Twitter data - dating back to the first tweet - using a rule-based filtering system to deliver complete coverage of historical Twitter data. This yielded a dataset of 5,299,319 tweets.

Accounts in our dataset have an average of 35,021 followers and 4,123 friends. Most accounts in our dataset have been on Twitter for a long period of time-3,345 days or almost ten years on average. Tweets sent by these accounts receive high levels of engagement. We find that on average each users' tweets in our data are retweeted 626 times and liked or favorited 870 times, demonstrating the importance of Twitter to Venezuelan politics. In addition to our data-collection approach, which involved manually identifying each account, the fact that the accounts we identified have been active for a long time, have large followings, and high levels of engagement increases our confidence that they are authentic Twitter users - rather than bots or trolls. ${ }^{12}$

11. The United States and Colombia are the most common destinations in our sample, though elites in our sample whose locations are known also went to Argentina; Bolivia; Brazil; Canada; Chile; the Czech Republic; El Salvador; France; Italy; Mexico; Peru; Spain; and Trinidad and Tobago.

12. While only $5 \%$ of the accounts in our dataset are verified, this is unsurprising given that many accounts belonging to well-known elites outside of the US and Western Europe have not been verified by Twitter (Paul et al. 2019). 


\section{Topics}

Our primary outcome variables are the percent of opposition leaders' tweets that reference several key topics: foreign action (meaning diplomacy, sanctions, or military intervention); local grievances related to the provision of services; protest; and stringent regime criticism, meaning content related to accusations of narco-trafficking, fascism, Cuban or Russian invasion, and extrajudicial repression. We additionally test whether exile changes the networks of those outside Venezuela. Among other ways of illustrating this mechanism, we track references to foreign actors.

To identify topics in our data, we use a word2vec model (Mikolov et al. 2013) trained on the entire corpus of tweets in our dataset. This includes both English and Spanish language tweets, the most common languages in the data, to reflect the fact that the language used by exiles may change as well. ${ }^{13}$ Word2vec models produce word-embeddings built on shallow neural networks, which rely on the collocation of words in texts to create vectors of terms that represent each word. They have been shown to capture complex concepts from analogies to changing cultural meanings and stereotypes associated with race, ethnicity, and gender (Rodman 2020). In particular, we begin with a set of seed words that we identify as being relevant to the concept of interest (e.g. "manifestación" for protest). We then used word embeddings to identify other words that are semantically related to our seed words in the data. Semantic similarity here is based on these words appearing in similar contexts, and can be computed using cosine similarity on the word embedding space (Gurciullo and Mikhaylov 2017). These dictionaries are then limited to the 100 most similar words and we remove overly general or irrelevant terms. ${ }^{14}$ Expert validation of tweets classified as referencing foreign action, protest, criticism of the regime, and service provision using our word2vec dictionary method suggests that between $93 \%$ and $97 \%$ of tweets were accurately classified across the four topics. ${ }^{15}$ For foreign intervention and sanctions, both controversial policy options, we additionally use a classifier to specifically identify support for these policies. ${ }^{16}$

13. We chose to train our word2vec model on the entire corpus of tweets in our dataset-rather than using common pretrained embeddings such as Spanish Wikipedia-because there is a great deal of language specific to Venezuelan Twitter including hashtags and online slang that we wanted to be sure to capture in our dictionary-based approach.

14. While this threshold of 100 words is somewhat arbitrary, going further down the list yielded almost entirely irrelevant words across topics. To capture additional words, we used multiple inputs reflecting similar concepts.

15. For more details on validation, see Appendix A.

16. We describe this in more detail in the results section and supplementary materials. 


\section{Empirical Strategy}

\section{Fixed Effects Models}

To identify the relationship between exile and online behavior, we exploit both variation between exiles and those who remain in country and changes in exiles' behavior in the months before and after they leave Venezuela. Our main analyses transforms our tweet-level dataset into a panel, by aggregating posts to the month-individual level, which helps prevent unduly weighting the tweets of frequent posters. Our central dependent variables are the percent of tweets related to a given topic or subtopic (for example, the percent of tweets by an opposition leader in a given month referencing sanctions). The median number of tweets per month for activists in our sample is $98 .{ }^{17}$

Our main specification uses two-way fixed effects to estimate the relationship between exile and online dissent, while accounting for common time shocks and time-invariant user characteristics. Our independent variable is whether a user was in exile in a given month, while our key dependent variable is the percent of posts on a given topic:

$$
Y_{i t}=\beta_{1} \text { Exile }_{i t}+\lambda_{i}+\eta_{t}+\beta_{2} X^{\prime}+\epsilon_{i t}
$$

The coefficient of interest is $\beta_{1}$, representing the effect of individual $i$ 's exile on tweeting about this topic. $Y_{i t}$ is our dependent variable, the percent of posts about a given topic that individual $i$ tweets in month $t$. The key independent variable is Exile $e_{i t}$, a binary indicator for whether an individual spent that month in exile. $\lambda_{i}$ are individual fixed effects, which account for time-invariant characteristics, and $\eta_{t}$ are month fixed effects, which account for common time shocks. $X^{\prime}$ are the number of tweets per month, accounting for variation in rates of tweeting. Standard errors are clustered at the individual level.

The central requirement for interpreting results causally is that exiled activists would have, in the absence of treatment, behaved similarly to those who remain in country. While an untestable assumption, in traditional difference-in-differences designs, we may establish this by demonstrating parallel trends before treatment. Since our treatment is staggered, we can use an event study design, which replaces the binary independent variable with leads and lags for the months until or since exile: ${ }^{18}$

17. We do not include months where a Twitter account was inactive, to avoid conflating periods where a given topic was not discussed and those where an activist did not tweet. Exile has no effect on tweet volume, and results hold when including these months (Appendix B).

18. In the main estimation and in the body of this article, we use only exiles in the base year, effectively comparing them to themselves. An alternative is to include all in-country activist months in the base year. 


$$
Y_{i t}=\sum_{\substack{n=-6 \\ n \neq-1}}^{n=11} \beta_{n} I_{i t}^{n}+\lambda_{i}+\eta_{t}+\beta_{2} X^{\prime}+\epsilon_{i t}
$$

We include dummies $I_{i t}^{n}$ for the six months prior to exile and the 12 months following, with the comparison year the month directly prior to an individual leaving the country. $\beta_{n}$ are thus the $n-1$ coefficients of interest. $\lambda_{i}$ are individual fixed effects accounting for timeinvariant characteristics, and $\eta_{t}$ are month fixed effects, to adjust for common time shocks. As above, we include the number of tweets in a given month. Estimated lead coefficients that are non-zero suggest violation of parallel trends. This also allows us to see the dynamic effects of exile over time. Since event studies are less appropriate for rare outcomes, we show these plots only for the major categories we track (calls for foreign action, discussion of protest, criticism of the regime, and mentions of foreign actors).

Still, exile is non-random, dependent on characteristics of the activist and more likely during periods of regime instability. Exile may target those members of the opposition most likely to be affected by leaving the country: for example, the government may want to push out particularly stringent or outspoken opposition activists, but these may be the most likely to even more vociferously criticize the government when safely overseas. The regime may force an individual to flee because they were increasingly critical of Maduro, in which case we may see a spurious relationship between exile and behavior. In addition to exploring pre-trends and anticipation effects in our event study design, however, this concern is lessened by the nature of our sample: these are individuals whose political beliefs are widely known, and who openly stand with the opposition.

To provide further confidence in results, we show that results hold when including an individual-specific linear time trend, which accounts for possible activist-specific trends in the dependent variable. Given concerns about the interpretation and validity of two way fixed effects, we also show pooled results that control for month but not unit fixed effects, to account for major nation-wide events like protests and elections (Imai and Kim 2020). In Appendix B we additionally show the results of robustness tests related to new literature on the problems of staggered treatment timing in difference-in-differences designs.

We show results hold using this alternative specification in Appendix B. 


\section{Results}

This section provides evidence that exile significantly increases Twitter discussions of foreign policy solutions to Venezuela's crisis and harsh criticisms of the regime; by contrast, it reduces discussions of local grievances and protests. In line with our theory, this suggests that exile shifts opportunities for dissent and influence, leading activists to target their messages more to foreign rather than domestic audiences. To provide further evidence for this mechanism, we demonstrate that across multiple metrics exile is associated with a significant increase in discussions of and interactions with foreign entities.

\section{Calls for Foreign Action}

We argue that exiles increasingly turn to foreign-led policies to solve Venezuela's crisis. In order to demonstrate this, as described we built word2vec dictionaries related to three major foreign policy options proposed for Venezuela: military intervention, sanctions, and diplomacy. Military intervention encompasses references to foreign military involvement by the US or an international coalition, both direct and indirect (e.g. "all options are on the table"); naval blockades; and forceful humanitarian intervention. References to military intervention are in general quite rare, with .12\% (6,277) of our 5 million tweets mentioning them. Sanctions include both targeted and generalized sanctions against the regime or the country, totaling $.54 \%$ of tweets $(28,463)$. Diplomacy includes references to diplomatic efforts, international pressure, international dialogue, or an internationally negotiated transition. $1.33 \%$ of tweets $(70,278)$ discuss international diplomatic efforts. Example tweets about foreign-led policies include the following:

- A military intervention by nationals supported by foreigners would not be a setback from the current situation. The setback would be to let criminals continue to exterminate our population and to only confront them with non-violence \#LibertyOrNothing.

- Despite the efforts of those linked to the \#Caracas regime in \#WashingtonDC to eliminate the sanctions, the administration of @realDonaldTrump continues to punish members of organized crime that govern \#Venezuela \#Sanctions \#Justicia

- RT @jguaido: At last I can report that we have already established contact with our international allies to evaluate collaborative proposals for Venezuela. We are looking for help for our people.

Figure 1 demonstrates that references to foreign policy actions increase significantly with exile. Within the first two months of leaving the country, they became significantly more 
likely to discuss international policy solutions for the Venezuelan crisis, and this effect persists for a full year after exile. The left panel shows coefficient plots for our fixed effects models (two-way fixed effects, two-way fixed effects with a unit-specific linear time trend, and month fixed effects only). Results show the percentage point change in discussions of each topic after exile, relative to activists who remained in Venezuela. While some of these figures appear quite small, relative to the amount the topics are discussed, the substantive effects are sizable. Overall, after exile the amount that activists talk about foreign policy topics more than doubles.

Figure 1: Exile and Discussions of Foreign Action
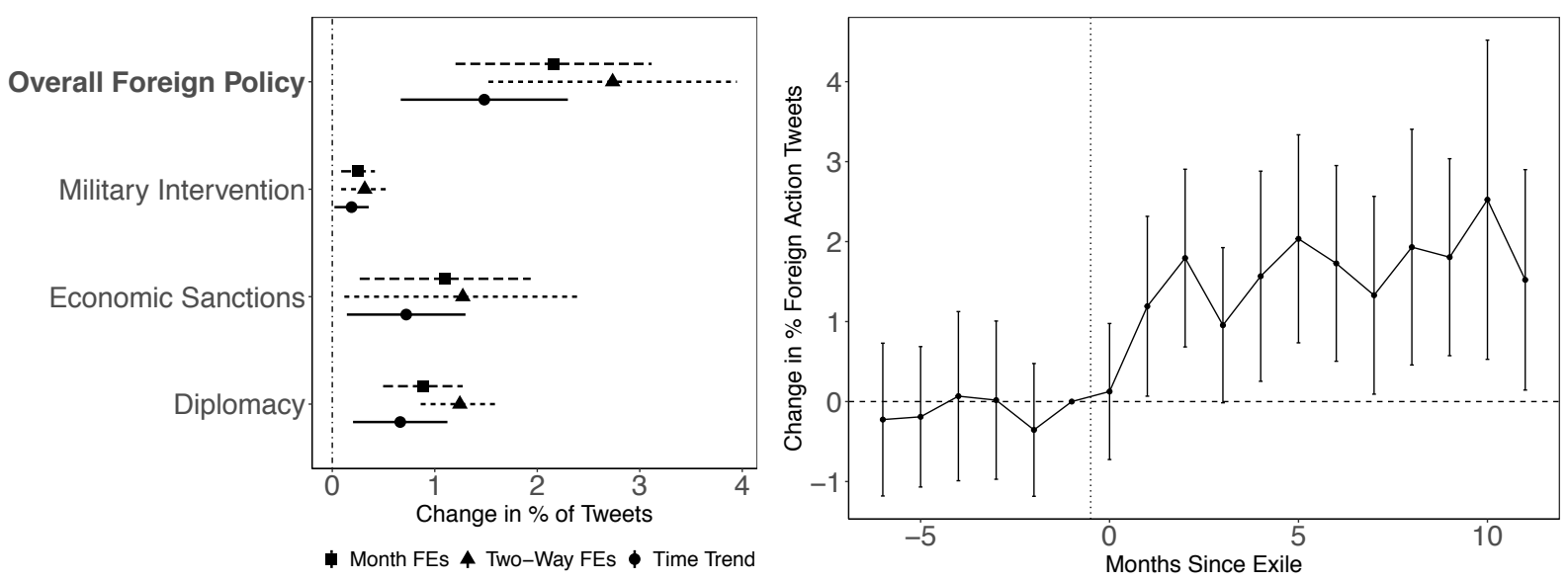

Left panel: Coefficient plots for models using two-way fixed effects, two-way fixed effects plus a unit-specific time trend, and month fixed effects only. Standard errors and confidence intervals are robust and clustered at the individual level. Right panel: Event study plots estimating leads and lags for exile, using the month immediately prior as the comparison period. Results demonstrate that exile is associated with a significant increase in discussions of foreign policy solutions for Venezuela's crisis.

While these results are driven by all mentions of these foreign actions identified using our dictionary approach, they do not automatically express a policy position. While reading the tweets in our dataset suggests that references to diplomacy are almost always positive, positions expressed about military interventions and sanctions, two aggressive and controversial foreign policy measures, are more diverse. Exiled individuals might be increasingly arguing against these policies, arguing for them, or neutrally sharing information related to these options. To test this, we hand-coded a set of 2,000 tweets identified as relating to military intervention and 2,000 tweets related to sanctions, asking coders to assess whether (1) a particular tweet was relevant to the topic and (2) whether it spoke of military intervention or sanctions positively, negatively, or neutrally (see Appendix A). We then trained Naive Bayes classifiers to first ascertain whether tweets were relevant to either military interventions or sanctions and then to label each tweet about military interventions or sanctions according 
to the sentiment it expressed.

This enables us to see that our results are mainly driven by an increase in supportive statements related to military intervention and sanctions, suggesting that exiled activists increasingly espoused aggressive foreign policy measures. Of tweets referencing military intervention, we identified $88.3 \%$ as relevant; of these, $58.2 \%$ spoke positively and $14.2 \%$ spoke negatively of military intervention. $90.8 \%$ of tweets we initially linked to sanctions were classified as relevant, with $34.7 \%$ supportive of sanctions and $2.7 \%$ referencing them negatively. ${ }^{19}$ More formally, we demonstrate in Appendix A that our results hold when including only statements positively referencing aggressive foreign policies. Exiles do not simply engage more with these policies, but make more public statements in support of such actions.

Our results also provide some descriptive evidence that the feasibility of different foreign policy options affects uptake by members of the opposition. Appendix A shows the rate of discussion for our topics over time. Breaking this down further by type of foreign policy, we see an increase in discussions of military action when Trump is president - providing suggestive evidence that the effects discussed here will vary by the foreign policy options considered available to exiles.

\section{Local Grievances}

Our theory additionally suggested that exile should change the degree to which exiles focus on issues and activism at the local level. Just as exiles may recognize the new opportunities afforded by going abroad, old pathways of influence may be less effective from outside of the country. Activists abroad should also be less aware of specific local events on the ground, and less active in organizing domestic opposition directly. Opponents frequently criticize the Venezuelan government for widespread hunger, lack of water, intermittent electricity, gas shortages, and other failures to provide basic services. $5.5 \%$ of tweets $(293,596)$ reference the provision of such services. Examples include, "The government shows, once again, its inability to operate and maintain public services" and "Because of years of abandonment by @Hidrocentro2011, today we Carabobeños live a tragedy, more than 20 days without water in our communities \#CaraboboSinAgua."

We additionally argue that exiled activists will be less focused on domestic mobilization. Opposition abroad are no longer present to organize and participate in collective action,

19. The large number of neutral tweets about sanctions in our dataset is due to the sharing of news articles or headlines referencing sanctions without taking a clear stance. 
and should thus discuss it somewhat less. While Venezuela has a strong history of national protests, moreover, many happen at a much smaller scale in response to local issues (BBC 2020). We expect that differences between activists at home and abroad will largely be driven by the degree to which domestic activists are involved in organizing protests and engaging in local collective action. Exiles are likely to remain more engaged in major and national protest, including through tweets of support. While difficult to test quantitatively, qualitative evidence offers some support. An example tweet about protest reads: "We are now arriving at \#Chacaito alongside the brave people of \#Caracas to join this concentration. \#100DaysOfResistanceForVenezuela." Another post states: "\#TACHIRA. San Pedro del Rio, Autopista San Cristóbal-La Fría, reported road closure due to protest against the shortage of domestic gas and continuous electricity cuts."

Figure 2 demonstrates that criticisms related to service provision drop significantly after exile, an effect that persists through the year following. Relative to the mean rate at which these topics were discussed, service provision-related criticisms dropped by about half. This suggests that exiles become less focused on these local grievances, as their international networks strengthen and their connection to local politics is reduced. Figure 3 shows that exile is associated with a decrease in discussion of domestic protest. The effects are smaller and noisier than for references to foreign actions or service provision, particularly for the event study plot. Nevertheless, our main specification suggests that there is an approximately one percentage point drop in discussions of protest after leaving the country, compared to an overall mean of $4.9 \%$ of tweets $(259,840)$ referencing mobilization.

\section{Criticism of the Regime}

We expect that exile should also be associated with an increase in harsh criticisms that target the legitimacy of Maduro's regime directly. Such criticisms can be more safely made from abroad rather than domestically, and they may be more appealing to international audiences. We track four types of specific criticisms. Narco-state criticisms focus on references to narcotrafficking and Maduro's links to drug money. 2.14\% of tweets $(113,563)$ use such terms. Dictator criticisms focus on accusations of fascism or dictatorship, making up $4.96 \%$ of tweets $(262,670)$. Cuban/Russian Influence critiques play up the role of Cuba and Russia in supporting the Maduro regime and appear in $1.86 \%$ of posts $(98,529)$. Repression references political killings, disappearances, imprisonment, torture, home searches, and other forms of state violence. $4.45 \%$ of tweets $(235,780)$ mention repression. ${ }^{20}$ Example tweets include:

20. We do not include exile, since this may functionally increase after activists leave the country (Appendix A) demonstrates that terms related to exile are increasingly used following activists leaving the country). 
Figure 2: Exile and Service Criticisms
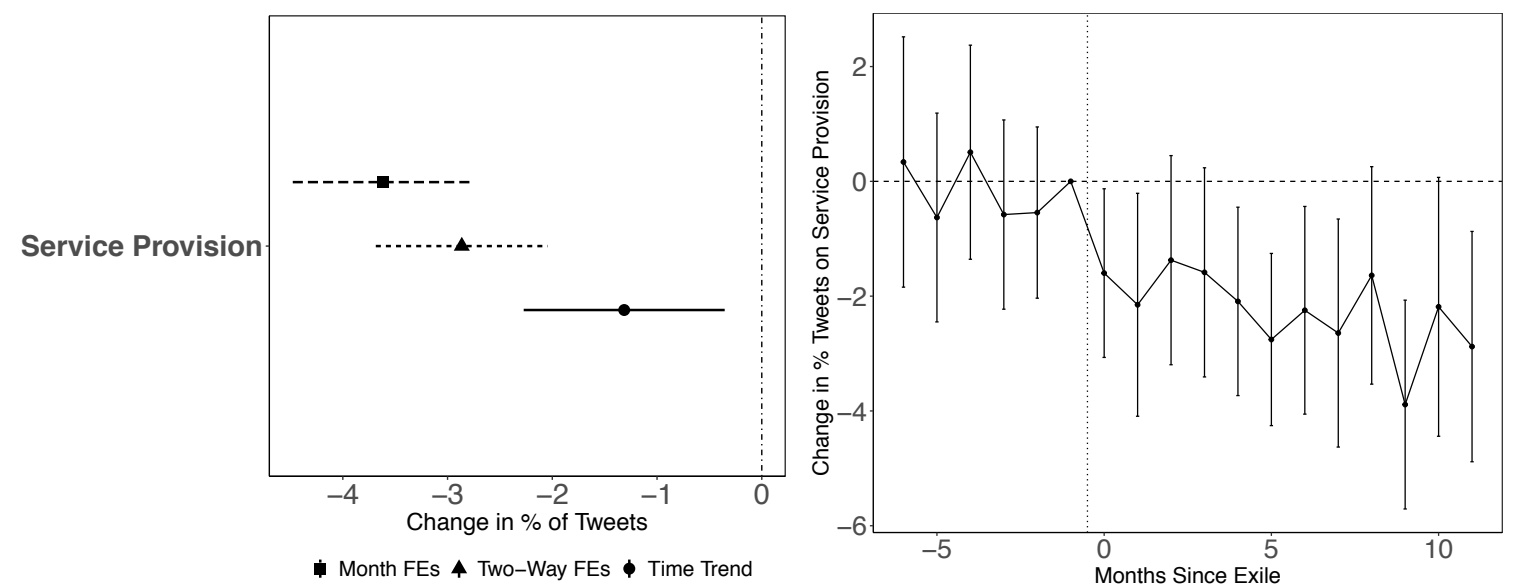

Left panels: Coefficient plot for models using two-way fixed effects, two-way fixed effects plus a unit-specific time trend, and month fixed effects only. Standard errors and confidence intervals are robust and clustered at the individual level. Right panel: Event study plots estimating leads and lags for exile, using the month immediately prior as the comparison period. Results demonstrate that more domestically-focused critiques of service provision fall after exile.

Figure 3: Exile and Protest

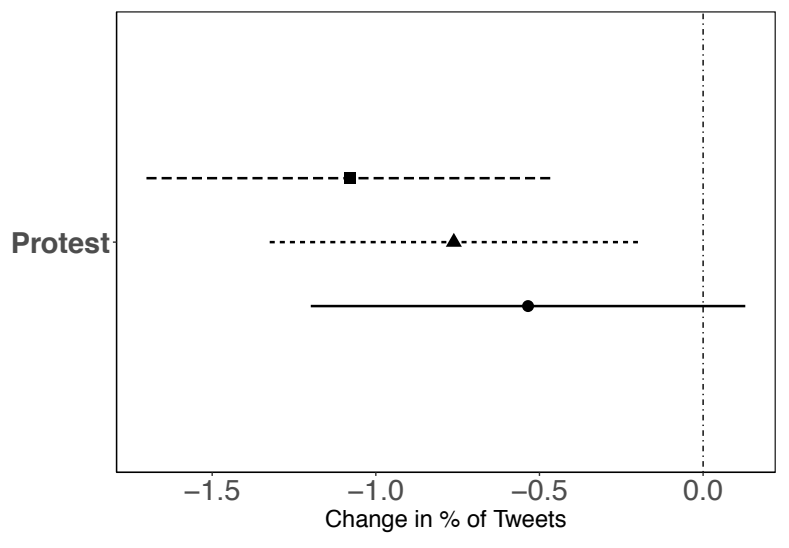

Month FEs 4 Two-Way FEs $\bullet$ Time Trend

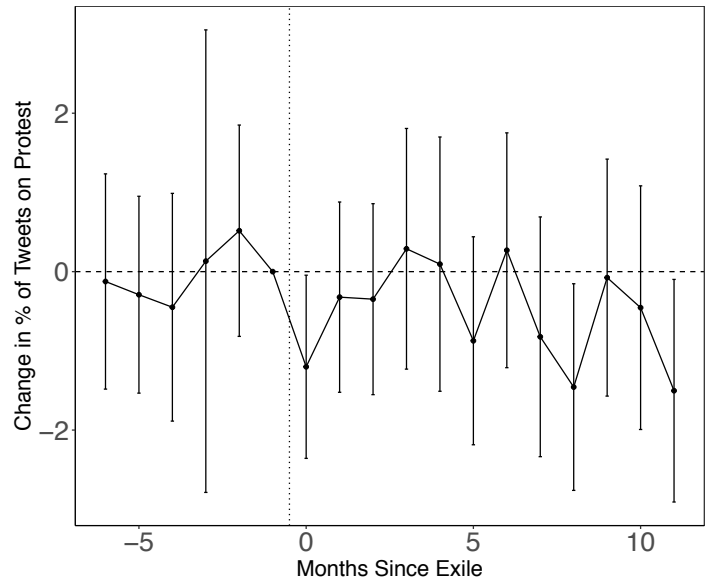

Left panel: Coefficient plots for models using two-way fixed effects, two-way fixed effects plus a unit-specific time trend, and month fixed effects only. Standard errors and confidence intervals are robust and clustered at the individual level. Right panel: Event study plots estimating leads and lags for exile, using the month immediately prior as the comparison period. Though results are noisy, they demonstrate a drop in discussions of mobilization after exile.

- 7,186,170 Venezuelans vote YES to democracy, YES to the Constitution, YES to Nicolás Maduro's narco-regime leaving Miraflores.

- This prosecutor is used by and part of the Repressive Structure of Maduro the Usurper, he will never appoint prosecutors to investigate the murder of protestors, extrajudicial executions, torture, etc.

- The Venezuela problem is not just political, as we face a dictatorship supported by 
Russia.

Figure 4 demonstrates that harsh criticism of the regime increases with exile. This aligns with both reduced self-censorship among activists, and the potential strategic adjustment of criticisms to focus more on critiques of interest to international audiences. The flow of cocaine through Venezuela, and high-level Venezuelan officials' involvement in the drug trade, is of particular importance to U.S. policymakers, for example (Ramsey and Smilde 2020).

Figure 4: Exile and Criticism
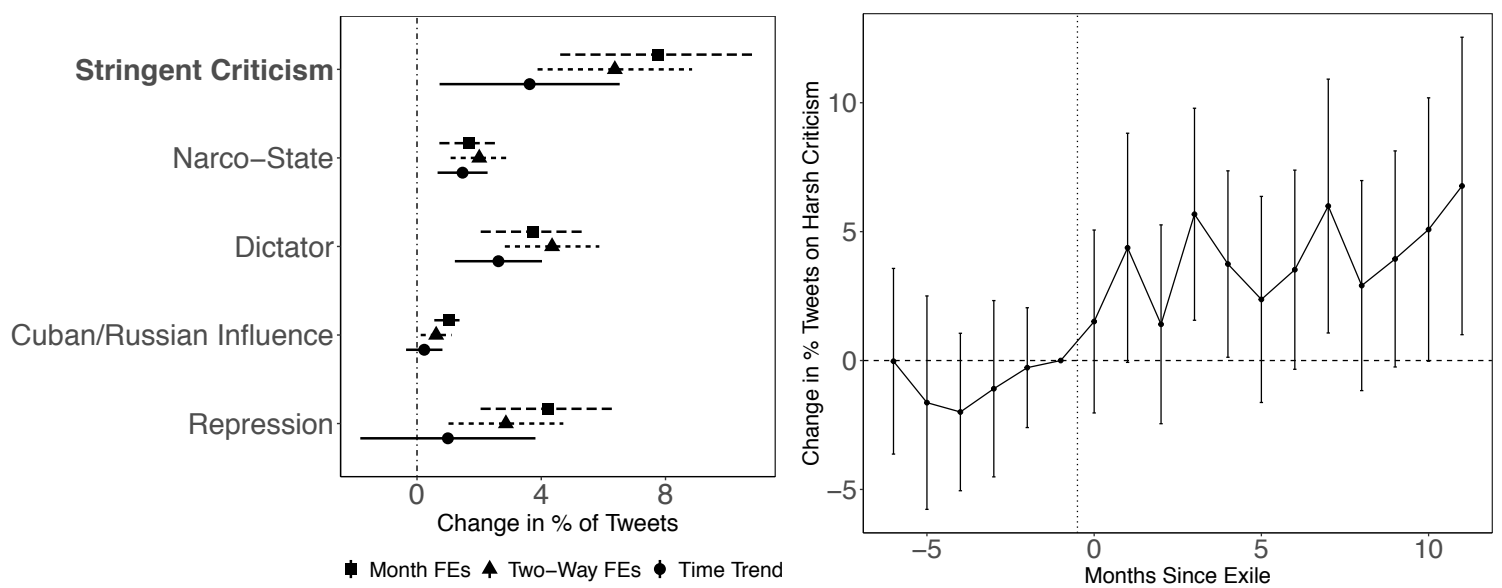

Left panel: Coefficient plots for models using two-way fixed effects, two-way fixed effects plus a unit-specific time trend, and month fixed effects only. Standard errors and confidence intervals are robust and clustered at the individual level. Right panel: Event study plots estimating leads and lags for exile, using the month immediately prior as the comparison period. Results suggest an increase in stringent criticism after exile.

Our sample of activists in Venezuela is not exhaustive, and there may be concern that there is a fundamental difference between the treated and control groups that drive our findings. To reduce these concerns, in Appendix B we demonstrate that results hold when using only our most complete set of activists, elected deputies and mayors. We also show that the results hold when including only those elected more recently (since 2011), in case parts of our sample left politics. In case periods of imprisonment, especially those preceding exile, may be driving our findings, the appendix additionally demonstrates our results hold when excluding opposition activists imprisoned in the period our data covers. Given variation within the Venezuelan opposition, we additionally demonstrate that results hold when controlling for politicians' parties interacted with a linear time trend, or when restricting our sample only to members of the more hardline Voluntad Popular party. In addition, to ensure that our results are not being significantly skewed by a particular user or set of user, we show 
that results are stable when dropping each user in our sample in turn.

Recent research has also raised concerns about the causal interpretation of two-way fixed effects difference-in-differences designs with staggered treatment timing when effects are heterogenous across time (which is often likely to be the case) (Goodman-Bacon 2020; Callaway and Sant'Anna 2021; Imai and Kim 2020). The central concern is that negative weights may be assigned when treatment effects and timing vary because already-treated units may serve as control groups. This is of somewhat less concern in our design because our sample of never-treated individuals is large, but we nevertheless perform several robustness checks to ensure the validity of our findings in Appendix B. First, we show the results of a GoodmanBacon decomposition, which demonstrates that our estimates are similar regardless of the timing of treatment, and weights are similar across treatment periods. We then show results hold using the Callaway and Sant'Anna (2021) estimator, for a "dynamic" event study specification. ${ }^{21}$ Additionally, we show that our results hold when excluding those who went into exile early, prior to the start of our tweet data, and when including only those who were exiled later in the regime (after 2017). Moreover, our results hold using t-tests comparing the percent of tweets by exiles about each topic in the period preceding and following exile. While simply descriptive, this helps reduce concerns that our results are driven by modeling decisions.

\section{Mechanism: Increased Engagement with Foreign Actors}

One pathway through which we expect exile to change the content of dissent is activists' increased engagement with and focus on international communities. As their networks become internationalized, activists may tailor messaging to this audience and may increasingly engage with the policy options available to their host country. We provide evidence for this in multiple ways. First, Figure 5 shows that Foreign Terms (such as references to other Latin American countries, the U.S., and European nations) increase following exile. While this measure encompasses many countries, we also show that mentions of the United States alone - the most popular destination country for Venezuelan exiles - rise as well. These effects begin shortly after exile, and persist through the year, with no evidence of a pre-trend in the event-study plot.

Second, the left panel of Figure 5 also shows the effect of exile on Foreign Engagement. To

21. The exception is harsh criticism, which remains substantively stable but falls below conventional levels of significance with the Callaway and Sant'Anna (2021) estimator. As we show in the Appendix, this is largely due the effect strengthening over time. 
Figure 5: Exile and Foreign Actors
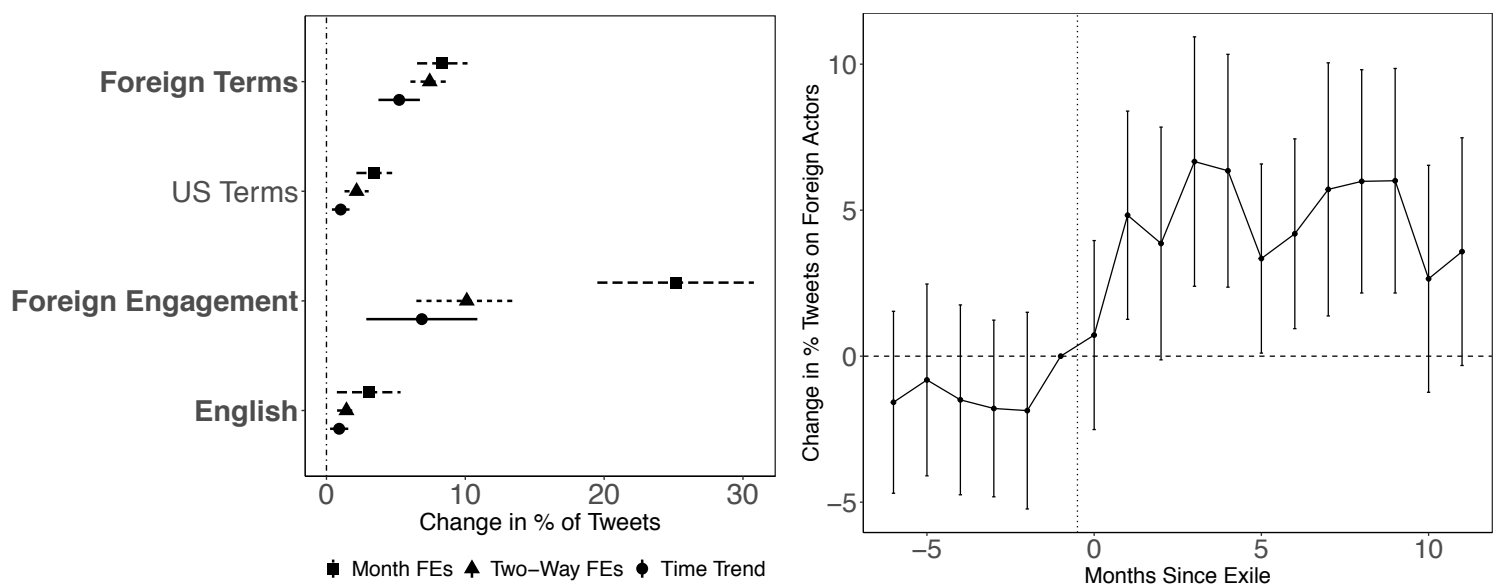

Left panel: Coefficient plot for models using two-way fixed effects, two-way fixed effects plus a unit-specific time trend, and month fixed effects only. Standard errors and confidence intervals are robust and clustered at the individual level. Foreign engagement uses only tweets “@”ing a user self-reported to live in Venezuela or overseas. Right panel: Event study plot estimating leads and lags for exile, using the month immediately prior as the comparison period. Results demonstrate that references to and engagement with foreign actors increases following exile.

measure this, we collected the Twitter handles of all users that the activists in our sample tweeted at or replied to. Where available, we then used the self-reported location information to identify users who lived abroad or in Venezuela, restricting our sample to only those cases where location information was available. Our results demonstrate that exiled activists increasingly associated with Twitter users living abroad, confirming that their networks become more international. We also show that exiles are more likely to tweet in English, one signal of exiles strategically positioning themselves in the international community.

Finally, we demonstrate that exile increases references to host country nations. Using our coding of exiles' destinations overseas, we interact our binary independent variable for whether a user was in exile in a given month with whether they live in the United States or Colombia, the most common destinations. Our dependent variables are references particularly to these nations. Overall, all exiles were more likely to reference foreign actors than those who remained in Venezuela. But relative to those who went to other countries, Venezuelans in the U.S. were more likely to use terms relating to the United States; Venezuelans in Colombia were more likely to reference Colombia-related terms. In Appendix A, we additionally explore results broken down by exiles' host state. However, there are no significant differences between exiles living in the United States versus other locations, which may be a reflection of an underpowered sample when splitting exiles by destination, or a degree of ideological similarity among the international networks and diaspora communities that exiles join. 
Figure 6: Exile and Destination

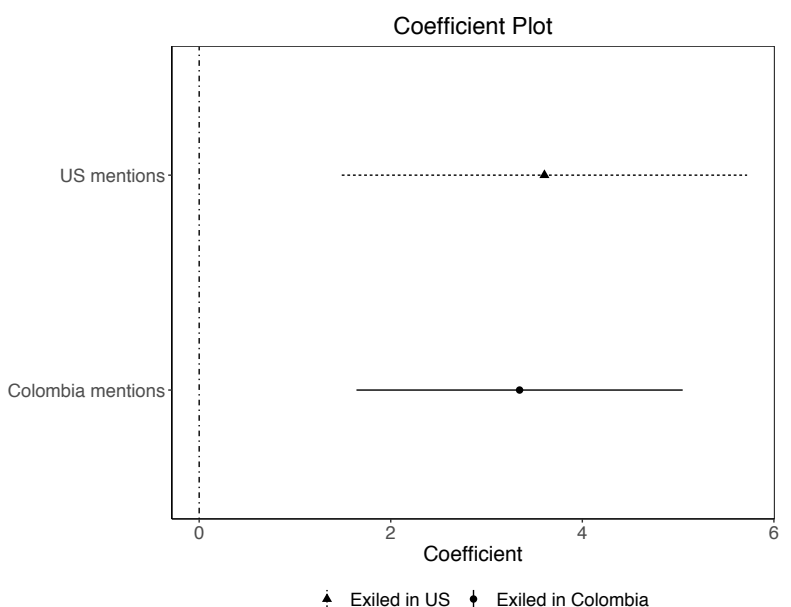

Coefficient plot regressing mentions of common host destinations (the U.S. and Colombia) on whether the user was in exile in that country in a given month. Coefficients show the effect of exile on mentions of the host country, relative to those in exile in other states. Models use two-way fixed effects with robust standard errors clustered at the individual level. Though all exiles are more likely to mention foreign nations, this effect is particularly pronounced for an activist's host country.

Exiles and observers point to the effects of this internationalization - and particularly socialization into a new political community - as central to why leaving Venezuela changes expressed attitudes. The Venezuelan diaspora focuses a great deal on shaping foreign policy towards Venezuela, in the process becoming much more engaged with political actors in their host country (Noriega 2014). They also become more integrated into a broader diaspora: one former US official noted that for exiles, the diaspora "becomes their tribe and identification." Expressing more centrist views towards the Maduro regime abroad, one former exile noted, was "almost unacceptable." 22 This is in part enforced through social media, and particularly Twitter, where deviation may be met with claims of "chavismo"(Padgett 2017).

This is not the only mechanism underlying the change in how exiles communicate. Exiles refer to weakened ties with on-the-ground politics as a source of the divergence in attitudes after leaving. Toro (2020) describes how, by situating activists out of the country, exile may lead to divergence between the opposition at home and abroad: "How dare [I] pass judgment ... from the comfort of a Montreal exile, where the water always works, the power never goes out and nobody throws you in jail for thinking the wrong thought?... How dare anyone not in Venezuela do that?" Dissidents are also freer to express themselves, with one former politician explaining, "[outside Venezuela], there's no political cost to doing or saying

22. Interview provided by the International Crisis Group, September 2020. 
anything." ${ }^{23}$ While reduced self-censorship and less fear of government reprisals certainly play a role in the findings documented here, it should be noted it is unlikely to be the only mechanism: it cannot alone explain the increased focus on foreign rather than domestic issues.

\section{Conclusion}

In this article, we demonstrate that exile changes how activists express dissent. Being overseas opens new opportunities for exiles to influence foreign governments and freely express themselves. However, it also weakens activists' ties to local networks and reduces their awareness of day-to-day activities at home. As a result, we argue that going abroad should make exiles increasingly focused on foreign policy interventions in their home state; less attuned to local grievances; and more willing to be harshly critical of the regime. Drawing on an original dataset of Venezuelan opposition figures and their Twitter histories, we provide evidence in support of these theoretical expectations. We also find that these changes are in part due to the increasingly international networks that exiles join when they go abroad, showing across several metrics that activist engagement with foreign entities significantly increases following exile.

This article contributes to our understanding of the consequences of repression, and the relationship between repression and dissent more broadly. While decades of social science literature have explored the dissent-repression nexus, empirical findings have often been contradictory, prompting scholars to call for disaggregating by type of repression, by space, and by time to better explain the dynamic relationship between repression and dissent (Chenoweth, Perkoski, and Kang 2017; Davenport 2007; Davenport and Inman 2012; Davenport and Moore 2012; Pan and Siegel 2020). Our temporally granular individual level data enables us to examine the political consequences of exile - a ubiquitous but understudied form of repression in the political science literature.

Research on how individuals respond to repression typically focus on more violent methods, like detention or killings (Bautista 2015; García-Ponce and Pasquale 2015; Rozenas and Zhukov 2013; Young 2020). Exile fundamentally differs from these methods, however, because opposition abroad often continue their activism in a different setting, with reduced fear for their physical integrity rights. A large body of research has highlighted how diaspora communities from a wide variety of home and host country governments have used brokerage,

23. Interview provided by the International Crisis Group, September 2020. 
framing, ethnic outbidding, lobbying, coalition-building, and the diffusion of ideas to shape foreign policies and alter outcomes in their home countries (Shain 1988, 1994, 2002; Adamson and Demetriou 2007; Adamson 2013; Koinova and Karabegović 2019; Koinova 2014, 2011; Moss 2021; Girard and Grenier 2008). By focusing on well-known, elite dissidents - actors who are particularly well-positioned to impact policy - and quantitatively testing the effect of exile on individual-level behavior, our work provides an important contribution. Our study also adds to a growing body of work on the effects of repression on online dissent. This includes research examining a range of repressive strategies from arrests (Pan and Siegel 2020) to censorship (Roberts 2018; King, Pan, and Roberts 2013) and computational propaganda (Woolley and Howard 2018). Here, we provide the first large-scale, quantitative study of the effects of exile on online opposition.

While our results are limited to the Venezuelan context, we expect our theory to hold for exiles emanating from repressive regimes, who share the goal of structurally changing their home-country government. Exiles or refugees who fled broader conflict should differ in their aims, and how they talk about their home countries. Members of distinct ethnic, nationalist, or social groups in exile may seek territorial or political change only for their population (Koinova 2009, 2014, 2021). For exiles fleeing repressive authoritarian or hybrid governments, however, we expect our theory to broadly hold - though we anticipate the specific ways in which discourse changes will vary based on home and host state context (Brinkerhoff 2016).

The types of foreign policy interventions that exiles advocate for will depend on feasibility, including how much they align with host country foreign policy goals. In many cases these include similar calls for sanctions, military intervention, and diplomacy that we observed in the Venezuelan context. For example, in 2003 Myanmar's exiled Prime Minister called for increased sanctions against the military government (Humhreys 2003). A group of exiled Iranian dissidents supported the Trump administration's policy of "maximum pressure," including widespread sanctions (Behravesh 2019). Cuban exiles have repeatedly called for similar interventionist policies (Grenier 2017) and Iraqi exiles notoriously lobbied for the 2003 US invasion of Iraq to depose Sadaam Hussein (Vanderbush 2009). For exiles from home countries that maintain close military or economic ties with the host state, calls for foreign action may focus on lighter-touch interventions such as Saudi activists' calls for Western governments and human rights organizations to condemn the kingdom's human rights abuses (Nowairah 2021). We expect that the degree to which more drastic action is feasible in a given home country will shape how extreme or moderate exiles' demands are. This 
may be one reason why some past work suggests that exiles express more extreme positions (Koinova 2009), and other findings suggest that exiles are more moderate than those in the home country (Müller-Funk 2016; Nugent 2020, 2022).

Although we expect moving abroad to make all exiles less connected to local networks and developments in their home countries, the degree to which exiles discuss local grievances and activism after exile may be shaped by the level of home-state control over speech. Restrictions on free speech affect the baseline rate at which dissidents at home can discuss certain topics related to local activism: for example, discussions of collective action are actively censored in China, though discussion of other grievances are allowed (King, Pan, and Roberts 2013). We might expect changes in the rate of discussions of local protest to look different if exiles are exiting a high-censorship environment than a lower-censorship environment. Discussion of local grievances and activism may also be moderated by exiles' perceived likelihood of return.

Finally, we expect that home state capacity for transnational repression may shape the willingness of exiles to harshly criticize the regime from abroad (Adamson 2020; Tsourapas 2021; Adamson and Tsourapas 2020; Dalmasso et al. 2018). Fear of repression abroad has been found to dampen anti-regime opposition among the Syrian, Libyan, and Yemeni diaspora communities, for example (Moss 2021). Among elite exiles, however, we might not observe the same dampening that researchers have found in the diaspora as a whole. Because elite exiles have long been well-known to their home-country regimes and faced severe threats that prompted them to leave the country, they will likely still feel freer to express criticism from abroad. Along these lines, Saudi activists have heavily criticized the regime and directly called out King Mohamed bin Salman for abuses even after the death of Jamal Khashoggi highlighted the regime's ability to target dissidents abroad (Nowairah 2021).

Considering the generalizability of our results opens up a number of issues for future research on the relationship between exile and dissent. First, we provide some descriptive evidence that opposition members tend to shift their rhetoric strategically in response to home and host country conditions. Future research should explore when diaspora communities' political aims shift. Second, authoritarian regimes have increasingly cut off access to social media sites for long periods of time; future research could explore how this changes who dissents online. Third, countries differ in the degree to which exile is a legal versus an ad hoc instrument. While in Venezuela most activists were forced out through threats or intimidation, future research could explore how different forms of exile affect changes in rhetoric. Fourth, the effects of exile may vary by continued vulnerability to the repressive regime. For exam- 
ple, exiles whose families remain in the home country, or who have significant assets there, may be more wary of changing their rhetoric. Additionally, future research should continue to explore how exile communities evolve over time and across generations - research begun with the study of Cuban Americans (Grenier 2017). We hope that future work will draw on similar methods and data sources in diverse global contexts to further our understanding of how one of the most ubiquitous forms of repression is shaping dissent in the digital age.

\section{References}

Adamson, Fiona B. 2013. "Mechanisms of diaspora mobilization and the transnationalization of civil war." Transnational dynamics of civil war: 63-88.

—. 2020. "Non-state authoritarianism and diaspora politics." Global Networks 20 (1): 150-169.

Adamson, Fiona B., and Madeleine Demetriou. 2007. "Remapping the boundaries of state and national identity: Incorporating diasporas into IR theorizing." European Journal of International Relations 13 (4): 489-526.

Adamson, Fiona B., and Gerasimos Tsourapas. 2020. "At home and abroad: Coercion-byproxy as a tool of transnational repression."

Andén-Papadopoulos, Kari, and Mervi Pantti. 2013. "The media work of Syrian diaspora activists: Brokering between the protest and mainstream media." International Journal of Communication 7:22.

Batista, Catia, Julia Seither, and Pedro C. Vicente. 2019. "Do migrant social networks shape political attitudes and behavior at home?" World Development 117:328-343.

Bautista, Maria Angélica. 2015. "Political Effects of State-led Repression: The Chilean Case." Working Paper. http: //www . barcelona-ipeg.eu/wp-content/uploads/2015/09/ Bautista-Repression-Sep15.pdf.

BBC. 2020. "Venezuela crisis: Anger over shortages triggers protests." September 30. https : //www. bbc.com/news/world-latin-america-54354225.

Behravesh, Maysam. 2019. "How the exiled Iranian opposition may actually be helping the Iranian regime." The Atlantic Council. https://www.atlanticcouncil.org/blogs/ iransource/how-the-exiled-iranian-opposition-may-actually-be-helpingthe-iranian-regime/. 
Borges, Julio. 2019. "Cuba Has Hijacked Venezuela." New York Times April 10. https : //www. nytimes.com/2019/04/10/opinion/venezuela-julio-borges.html.

Brinkerhoff, Jennifer M. 2009. Digital diasporas: Identity and transnational engagement. Cambridge University Press.

- 2011. "Diasporas and conflict societies: conflict entrepreneurs, competing interests or contributors to stability and development?" Conflict, Security and Development 11 (02): 115-143.

- 2016. Institutional Reform and Diaspora Entrepreneurs: The In-Between Advantage. Oxford University Press.

Callaway, Brantly, and Pedro HC Sant'Anna. 2021. "Difference-in-differences with multiple time periods." Journal of Econometrics 225 (2): 200-230.

Calvo, Ernesto. 2015. Anatomía política de Twitter en Argentina: Tuiteando \#Nisman. Buenos Aires: Capital Intelectual.

Careja, Romana, and Patrick Emmenegger. 2012. "Making Democratic Citizens: The Effects of Migration Experience on Political Attitudes in Central and Eastern Europe." Comparative Political Studies 45 (7): 875-902.

Carey, Sabine C. 2006. "The Dynamic Relationship between Protest and Repression." Political Research Quarterly 59 (1): 1-11.

- 2009. Protest, Repression, and Political Regimes: An Empirical Analysis of Latin America and Sub-Saharan Africa. Routledge.

Casey, Nicholas. 2019. “It Is Unspeakable': How Maduro Used Cuban Doctors to Coerce Venezuela Voters." New York TImes March 17. https://www.nytimes.com/2019/03/ 17/world/americas/venezuela-cuban-doctors.html.

Chenoweth, Erica, Evan Perkoski, and Sooyeon Kang. 2017. "State repression and nonviolent resistance." Journal of Conflict Resolution 61 (9): 1950-1969.

Christensen, Darin. 2018. "The Geography of Repression in Africa." Journal of Conflict Resolution 62 (7): 1517-1543.

Dalmasso, Emanuela, Adele Del Sordi, Marlies Glasius, Nicole Hirt, Marcus Michaelsen, Abdulkader S Mohammad, and Dana Moss. 2018. "Intervention: Extraterritorial authoritarian power." Political Geography 64 (May 2018): 95-104. 
Danitz, Tiffany, and Warren P. Strobel. 1999. "The Internet's Impact on Activism: The Case of Burma." Studies in Conflict and Terrorism 22 (3): 257-269.

Davenport, Christian. 2007. "State repression and political order." Annual Review of Political Science 10:1-23.

Davenport, Christian, and Molly Inman. 2012. "The state of state repression research since the 1990s." Terrorism and Political Violence 24 (4): 619-634.

Davenport, Christian, and Will H Moore. 2012. "The Arab Spring, Winter, and Back Again?(Re) Introducing the dissent-repression nexus with a twist." International Interactions 38 (5): $704-713$.

Davies, Wyre. 2016. "Venezuela's decline fuelled by plunging oil prices." $B B C$ February 20. https://www.csis.org/analysis/are-sanctions-working-venezuela.

Dunning, Thad. 2010. "Endogenous Oil Rents." Comparative Political Studies 43 (3): 379410.

EFE. 2017. "La Federación Farmacéutica Venezolana cifra la escasez de medicinas en un 85\%." January 27. https://www.efe.com/efe/america/sociedad/la-federacionfarmaceutica-venezolana-cifra-escasez-de-medicinas-en-un-85/200000133161928.

El Tiempo. 2019. "En Venezuela se han dado cerca de 50.000 protestas en la era Maduro." January 23. https://www. elnacional .com/sociedad/venezuela-han-dado-cerca50000-protestas-era-maduro_267707/.

Esberg, Jane. 2020. "Anticipating Dissent: The Repression of Politicians in Pinochet's Chile." Journal of Politics Forthcoming. https://www .dropbox.com/s/ghae0rel6skmc30/ Esberg_repressedpols_JOP_version.pdf?dl=0.

Eubank, Nicholas, and Dorothy Kronick. 2021. "Friends Don't Let Friends Free Ride." Quarterly Journal of Political Science 16 (4): 533-557.

Faiola, Anthony. 2018. "Venezuelan President Nicolás Maduro wins reelection amid charges of irregularities." Washington Post May 20. https : / / www . washingtonpost . com / world / the _ americas / crisis - weary - venezuelans - are-voting-in-electiondecried-as - a-maduro-power-grab/2018/05/20/cb7b579e-57d6-11e8-988907bcc1327f4b_story.html. 
Faiola, Anthony. 2019. "Guaidó says opposition overestimated military support for uprising." Washington Post May 4. https://www . washingtonpost.com/world/need-more-sol diers-venezuelas-guaido-says-opposition-overestimated-military-supportbefore-failed-uprising/2019/05/04/72561cb8-6e8b-11e9-bbe7-1c798fb80536_ story.html.

Faiola, Anthony, and Rachele Krygier. 2018. "Blackouts, hyperinflation, hunger: Maduro faces reelection as Venezuela deteriorates." Washington Post May 16. https://www . washingtonpost . com/world/the_americas/blackouts-hyperinflation-hungermaduro-faces-reelection-as-venezuela-deteriorates/2018/05/16/2ec5bb6056f5-11e8-9889-07bcc1327f4b_story.html.

Falke, Andreas. 2000. "EU-US Conflict over Sanctions Policy: Confronting the Hegemon." The European Foreign Affairs Review 5:139-163.

Friedman, Uri. 2019. "In Washington, the Venezuelan Opposition Has Already Won." The Atlantic February 19. https : / /www . theatlantic . com/international/archive / 2014/02/why-venezuelas-revolution-will-be-tweeted/283904/.

García-Ponce, Omar, and Benjamin Pasquale. 2015. "How Political Repression Shapes Attitudes Towards the State: Evidence from Zimbabwe." Working Paper. https://omarg arciaponce.com/wp-content/uploads/2013/07/GarciaPonce_and_Pasquale_2014. pdf.

Girard, Chris, and Guillermo J. Grenier. 2008. "Insulating an Ideology: The Enclave Effect on South Florida's Cuban Americans." Hispanic Journal of Behavioral Sciences 30 (4): $530-543$.

Goodman-Bacon, Andrew. 2020. "Difference-in-differences with Variation in Treatment Timing." National Bureau of Economic Research No. w25018. https ://www . nber . org/ papers/w25018.

Grenier, Guillermo J. 2017. "Engage or Isolate? Twenty years of Cuban Americans' Changing Attitudes towards Cuba - Evidence from the FIU Cuba Poll." Idées d'Amériques 10.

Gulotty, Robert, and Dorothy Kronick. 2020. "The Arbitrage Lobby: The Political Economy of Dual Exchange Rates." International Organization Forthcoming. https://papers . ssrn.com/sol3/papers.cfm?abstract_id=3192898. 
Gurciullo, Stefano, and Slava J Mikhaylov. 2017. "Detecting policy preferences and dynamics in the un general debate with neural word embeddings." In 2017 International Conference on the Frontiers and Advances in Data Science (FADS), 74-79. IEEE.

Henry, Laura, and Elizabeth Plantan. 2021. "Activism in exile: how Russian environmentalists maintain voice after exit." Post-Soviet Affairs: 1-19.

Hirschman, Albert O. 1978. "Exit, voice, and the state." World Politics 31 (1): 90-107.

Human Rights Watch. 2019. "Venezuela: Events of 2018." https://www.hrw.org/worldreport/2019/country-chapters/venezuela\#1dc307.

Humhreys, John. 2003. "Exiled PM urges EU sanctions against Burma." The Irish Times September 18. https://www. irishtimes.com/news/exiled-pm-urges-eu-sanction s-against-burma-1.376678.

Hussain, Muzammil M., and Philip N. Howard. 2013. "What best explains successful protest cascades? ICTs and the fuzzy causes of the Arab Spring." International Studies Review 14 (1): 48-86.

Imai, Kosuke, and In Song Kim. 2020. "On the Use of Two-Way Fixed Effects Regression Models for Causal Inference with Panel Data." Working paper. http://web.mit.edu/ insong/www/pdf/FEmatch-twoway . pdf.

International Crisis Group. 2020. "Imagining a Resolution of Venezuela's Crisis." Latin America and the Caribbean Report 79. https://www.crisisgroup.org/latin-americacaribbean/andes/venezuela/79-imagining-resolution-venezuelas-crisis.

- 2021. "The Exile Effect: Venezuela's Overseas Opposition and Social Media." Latin America and the Caribbean Report 86. https : / / www . crisisgroup . org/latinamerica-caribbean/andes/venezuela/086-exile-effect-venezuelas-overseasopposition-and-social-media.

2022. "Overcoming the Global Rift on Venezuela." Latin America and the Caribbean Report 93. https : / /www . crisisgroup .org/latin-america-caribbean/andes / venezuela/93-overcoming-global-rift-venezuela.

Karimzad, Farzad, and Lydia Catedral. 2018. "Mobile (Dis)connection: New Technology and Rechronotopized Images of the Homeland." Linguistic Anthropology 28 (3): 95-104.

Kendzior, Sarah. 2012. "The Uzbek Opposition in Exile: Diaspora and Dissident Politics in the Digital Age." 
King, Gary, Jennifer Pan, and Margaret E Roberts. 2013. "How censorship in China allows government criticism but silences collective expression." American Political Science Review: $326-343$.

Koinova, Maria. 2009. "Diasporas and democratization in the post-communist world." Communist and Post-communist studies 42 (1): 41-64.

—. 2011. "Diasporas and secessionist conflicts: the mobilization of the Armenian, Albanian and Chechen diasporas." Ethnic and Racial Studies 34 (2): 333-356.

—. 2014. "Why do conflict-generated diasporas pursue sovereignty-based claims through state-based or transnational channels? Armenian, Albanian and Palestinian diasporas in the UK compared." European Journal of International Relations 20 (4): 1043-1071.

—. 2021. Diaspora Entrepreneurs and Contested States. Oxford University Press.

Koinova, Maria, and Dženeta Karabegović. 2019. "Causal mechanisms in diaspora mobilizations for transitional justice." Ethnic and Racial Studies 42 (11): 1809-1829.

Kuran, Timur. 1991. "Now out of never: The element of surprise in the East European revolution of 1989." World Politics 44 (1): 7-48.

Lupu, Noam, Mariana V. Ramírez Bustamante, and Elizabeth J. Zechmeister. 2020. "Messaging Mistrust in Latin America." Journal of Democracy 31 (3): 160-171.

Mainwaring, Scott, and Aníbal Pérez Liñán. 2015. "Cross-Currents in Latin America." Journal of Democracy 26 (1): 114-127.

McKeever, David. 2020. Exiled Activism: Political Mobilization in Egypt and England. Routledge.

Michaelsen, Marcus. 2018. "Exit and voice in a digital age: Iran's exiled activists and the authoritarian state." Globalizations 15 (2): 248-264.

Mikolov, Tomas, Kai Chen, Greg Corrado, Jeffrey Dean, L Sutskever, and G Zweig. 2013. "word2vec." URL https://code. google. com/p/word2vec 22.

Morales, Alfredo Jose, Javier Borondo, Juan Carlos Losada, and Rosa M Benito. 2015. "Measuring political polarization: Twitter shows the two sides of Venezuela." Chaos: An Interdisciplinary Journal of Nonlinear Science 25 (3): 033114.

Morales, Juan S. 2020. "Perceived popularity and online political dissent: Evidence from Twitter in Venezuela." The International Journal of Press/Politics 25 (1): 5-27. 
Morselli, Davide, Stefano Passini, and Craig McGarty. 2021. "Sos Venezuela: an analysis of the anti-Maduro protest movements using Twitter." Social Movement Studies 20 (5): $509-530$.

Moss, Dana M. 2021. The Arab Uprisings Abroad. Cambridge University Press.

Müller-Funk, Lea. 2016. "Diaspora mobilizations in the Egyptian (post) revolutionary process: Comparing transnational political participation in Paris and Vienna." Journal of Immigrant \& Refugee Studies 14 (3): 353-370.

Munger, Kevin, Richard Bonneau, Jonathan Nagler, and Joshua A Tucker. 2019. "Elites tweet to get feet off the streets: Measuring regime social media strategies during protest." Political Science Research and Methods 7 (4): 815-834.

Noriega, David. 2014. "Miami's Venezuelans Are Starting to Drive U.S. Policy Like Their Cuban Neighbors." Buzzfeed News May 25. https://www . buzzfeednews . com/article/ davidnoriega/how-venezuelans-in-the-us-became-a-potent-political-force.

Nowairah, Nabeel. 2021. "Saudi Repression Strengthens Opposition Abroad." Carnegie Endowment for International Peace.

Nugent, Ciara. 2019. "Venezuelans are starving for information.' The battle to get news in a country in chaos." Time April 16. https://time.com/5571504/venezuela-internetpress-freedom/.

Nugent, Elizabeth R. 2020. After Repression. Princeton University Press.

- 2022. Exiles: how activists abroad make politics back home. In Progress.

Padgett, Tim. 2017. "Venezuelan Dictatorship Means Venezuelan Exiles Must Learn from Cuban Exiles' Mistakes." WRLN. https : / / www . wlrn . org/news / 2017-08-03/ venezuelan-dictatorship-means-venezuelan-exiles-must-learn-from-cubanexiles-mistakes.

Pan, Jennifer, and Alexandra Siegel. 2020. "How Saudi crackdowns fail to silence online dissent." American Political Science Review 114 (1): 109-125.

Paul, Indraneil, Abhinav Khattar, Ponnurangam Kumaraguru, Manish Gupta, and Shaan Chopra. 2019. "Elites tweet? Characterizing the Twitter verified user network." In 2019 IEEE 35th International Conference on Data Engineering Workshops (ICDEW), 278285. IEEE. 
Pérez-Armendáriz, Clarisa, and David Crow. 2009. "Do Migrants Remit Democracy? International Migration, Political Beliefs, and Behavior in Mexico." Comparative Political Studies 43 (1): 119-148.

Pierskalla, Jan Henryk. 2010. "Protest, Deterrence, and Escalation: The Strategic Calculus of Government Repression." Journal of Conflict Resolution 54 (1): 117-45.

Ramsey, Geoff, and David Smilde. 2020. "Beyond the Narcostate Narrative: What U.S. Drug Monitoring Data Says About Venezuela." Washington Office on Latin America March.

Rashbaum, William K., Benjamin Weiser, and Katie Benner. 2020. "Venezuelan Leader Maduro Is Charged in the U.S. With Drug Trafficking." New York Times March 26. https : //www . nytimes . com/2020/03/26/nyregion/venezuela-president-drugtrafficking-nicolas-maduro.html.

Roberts, Margaret E. 2018. Censored: distraction and diversion inside China's Great Firewall. Princeton University Press.

Rodman, Emma. 2020. "A Timely Intervention: Tracking the Changing Meanings of Political Concepts with Word Vectors." Political Analysis 28 (1): 87-111.

Rodrigues de Caires, Carlos M., and Jesús A. Sánchez Azuaje. 2018. "La superviviencia del autoritarismo en Venezuela: legados institucionales y estrategias mixtas (2013-2017)." Revista Andina de Estudios Politicos 8 (2): 48-71.

Rozenas, Arturas, and Yuri Zhukov. 2013. "Mass Repression and Political Loyalty: Evidence from Stalin's 'Terror by Hunger'”.' American Political Science Review 113 (2): 569-583.

Rudnik, Alesia. 2021. "The Belarusian Diaspora and its Role in Solving the Political Crisis." Stockholm Free World Forum.

Sanchez, Romy, and Edward Blumenthal. 2022. Exilios latino-americanos en el largo siglo $X I X$.

Service, Congressional Research. 2020. "Venezuela: Overview of U.S. Sanctions." August 20. https://fas.org/sgp/crs/row/IF10715.pdf.

Shain, Yossi. 1988. "Who is a Political Exile? Defining a Field of Study for Political Science." International Migration 26 (4): 387-400.

1994. "Ethnic diasporas and US foreign policy." Political Science Quarterly 109 (5): $811-841$. 
Shain, Yossi. 1999. Marketing the American creed abroad: Diasporas in the US and their homelands. Cambridge University Press.

- 2002. "The role of diasporas in conflict perpetuation or resolution." SAIS Review (1989-2003) 22 (2): 115-144.

Shen, Xiaoxiao, and Rory Truex. 2021. "In search of self-censorship." British Journal of Political Science 51 (4): 1672-1684.

Siegel, David A. 2011. "When Does Repression Work? Collective Action in Social Networks." The Journal of Politics 73 (4): 993-1010.

Silver, Laura, Aaron Smith, Courtney Johnson, Kyle Taylor, Jingjing Jiang, Monica Anderson, and L Rainie. 2019. "Mobile connectivity in emerging economies." Pew Research Center 7.

The Guardian. 2020. "One in three Venezuelans not getting enough to eat, UN finds." February 24. https : //www . theguardian . com/world/2020/feb/24/venezuela-hungryfood-insecure-un-world-food-program.

Toro, Francisco. 2020. "My Name is Francisco, and I Am a Toxic Exile." Caracas Chronicles October 1. https : / / www . caracaschronicles . com / 2020/10/01/my-name-is francisco-and-i-am-a-toxic-exile/.

Truex, Rory. 2018. "Focal Points, Dissident Calendars, and Preemptive Repression." Journal of Conflict Resolution 63 (4): 1032-1052.

Tsourapas, Gerasimos. 2021. "Global autocracies: Strategies of transnational repression, legitimation, and co-optation in world politics." International Studies Review 23 (3): 616644.

UNCHR. 2019. "Human rights in the Bolivarian Republic of Venezuela." https : //www . ohchr.org/EN/HRBodies/HRC/RegularSessions/Session41/Documents/A_HRC_41_ 18. docx.

UNHCR. 2019. "Refugees and migrants from Venezuela top 4 million: UNHCR and IOM." June 7. https : //www . unhcr .org/en-us/news/press/2019/6/5cfa2a4a4/refugeesmigrants-venezuela-top-4-million-unhcr-iom.html.

United Nations. 2019. "Venezuelans Must Resolve Crisis Themselves, Security Council Delegates Agree while Differing over Legitimacy of Contending Parties." Meetings Coverage and Press Releases February 26 (SC/13719). https : //www . un.org/press/en/2019/ sc13719. doc.htm. 
Vanderbush, Walt. 2009. "Exiles and the Marketing of US Policy toward Cuba and Iraq." Foreign Policy Analysis 5 (3): 287-306.

Waisbord, Silvio, and Adriana Amado. 2017. "Populist communication by digital means: presidential Twitter in Latin America." Information, communication Es society 20 (9): 1330-1346.

Wayland, Sarah. 2004. "Ethnonationalist networks and transnational opportunities: the Sri Lankan Tamil diaspora." Review of International Studies 30 (3): 405-426.

WLRN. 2017. "Venezuelan Regime Hunts Down Opposition Figures; More Expected In Exile Here." August 14. https : //www.wlrn .org/show/latin-america-report/2017-0814 / venezuelan-regime-hunts-down-opposition-figures-more-expected-inexile-here.

Woolley, Samuel C, and Philip N Howard. 2018. Computational propaganda: political parties, politicians, and political manipulation on social media. Oxford University Press.

World Food Program. 2020. "WFP Venezuela Food Security Assessment." https ://reliefw eb.int/report/venezuela-bolivarian-republic/wfp-venezuela-food-securityassessment-main-findings-data.

Wright, Thomas C., and Rody Oñate Zuñiga. 2007. "Chilean Political Exile." Latin American Perspectives 34 (4): 31-49.

Yeh, Emily T. 2007. "Exile Meets Homeland: Politics, Performance, and Authenticity in the Tibetan Diaspora." Environment and Planning D: Society and Space 25 (4): 648-667.

Young, Lauren E. 2019. "The Psychology of State Repression: Fear and Dissent Decisions in Zimbabwe." American Political Science Review 113 (1): 140-155.

—. 2020. "Who Dissents? Self-efficacy and Opposition Action after State-Sponsored Election Violence." Journal of Peace Research 57 (1): 62-76.

Zuckerman, Ethan. 2013. Digital cosmopolitans: Why we think the Internet connects us, why it doesn't, and how to rewire it. WW Norton \& Company. 


\section{Supplementary Appendix:}

How Exile Shapes Online Opposition:

Evidence from Venezuela 


\section{Contents}

$\begin{array}{ll}\text { A Additional Information } & 1\end{array}$

A.1 Expert Dictionary Validation . . . . . . . . . . . . . . . . . 1

A.2 Topics Over Time (Raw Data) . . . . . . . . . . . . . . . . . . . 2

A.3 Crowd-sourced Human Coding . . . . . . . . . . . . . . . . . . . 4

A.4 Classified Military and Sanctions Tweets . . . . . . . . . . . . 5

A.5 References to Exile . . . . . . . . . . . . . . . . . 6

A.6 Results by Location of Exile . . . . . . . . . . . . . . . . . 6

A.7 T-Test Results . . . . . . . . . . . . . . . . . . . . . 7

$\begin{array}{lr}\text { B Robustness Checks } & 8\end{array}$

B.1 Including Inactive Months . . . . . . . . . . . . . . . . . . 8

B.2 Changing Event Study Estimation . . . . . . . . . . . . . . . 8

B.3 Including Only Politicians . . . . . . . . . . . . . . . . . . . . 9

B.4 Political Prisoners . . . . . . . . . . . . . . . . . . . . . . . . . . . . 9

B.5 Political Party . . . . . . . . . . . . . . . . . . . . . . . . . 10

B.6 Robustness to Dropping Individuals . . . . . . . . . . . . . . . . . . 10

B.7 Bacon-Goodman Decomposition . . . . . . . . . . . . . . . . . . 11

B.8 Callaway and Sant'Anna . . . . . . . . . . . . . . . . . . . 11

B.9 Removing Early Exiles . . . . . . . . . . . . . . . . . . . . . . 15 


\section{Appendix A: Additional Information}

\section{A.1 Expert Dictionary Validation}

In order to ensure that our word2vec dictionary approach accurately classified tweets, we had a Spanish speaker with expertise in Venezuelan politics code a stratified random sample of 2000 tweets (500 classified in each topic) according to whether each tweet was correctly classified as relevant to criticism of the regime, foreign action, protest, or service provision. As Figure A1 below suggests, between 93 and $97 \%$ of tweets were coded by our expert coder as relevant across all four topics. Between 1 and $3 \%$ of tweets were coded as irrelevant, and between 3 and $4 \%$ of tweets were unclear across all four topics.

Figure A1: Expert Validation of Word2Vec Dictionary Classification

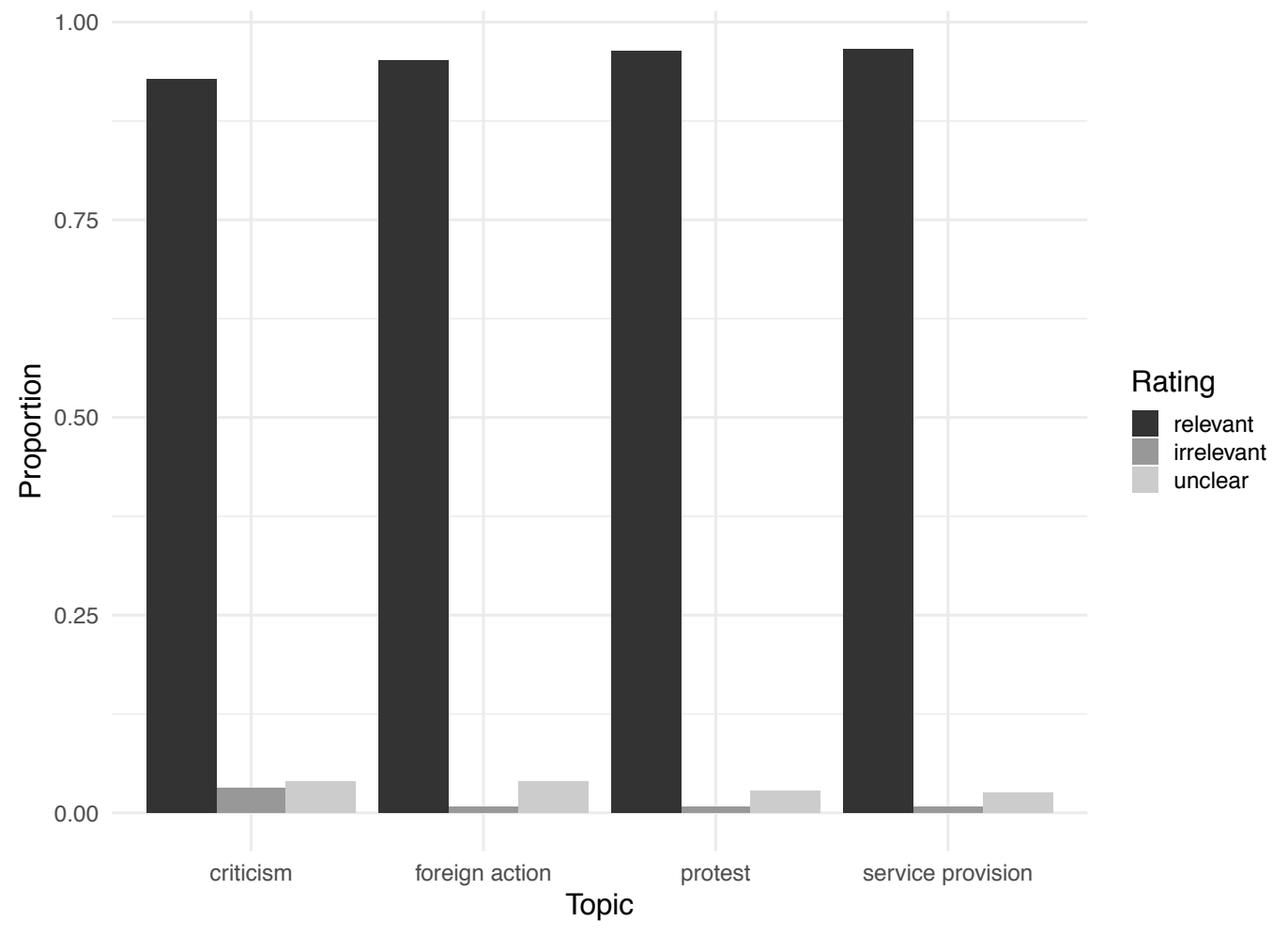




\section{A.2 Topics Over Time (Raw Data)}

Figure A2: Weekly Volume of Tweets Referencing Primary Topics

Foreign Policy

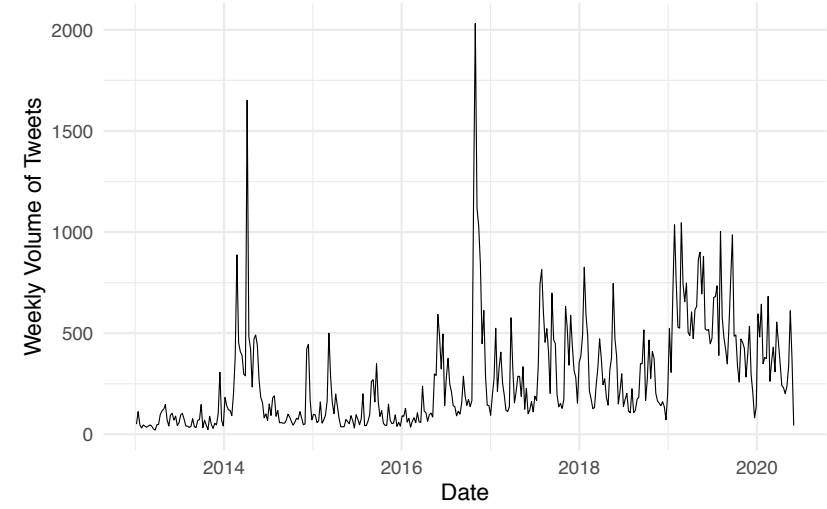

Protest

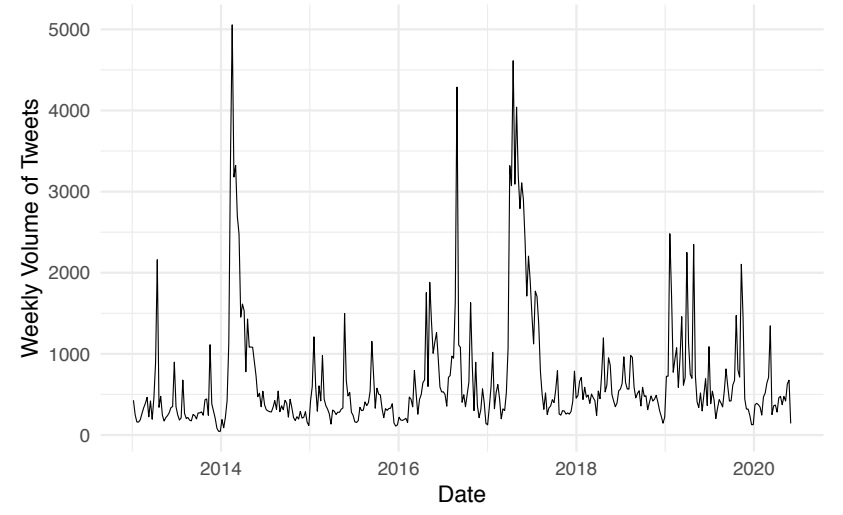

Service Provision

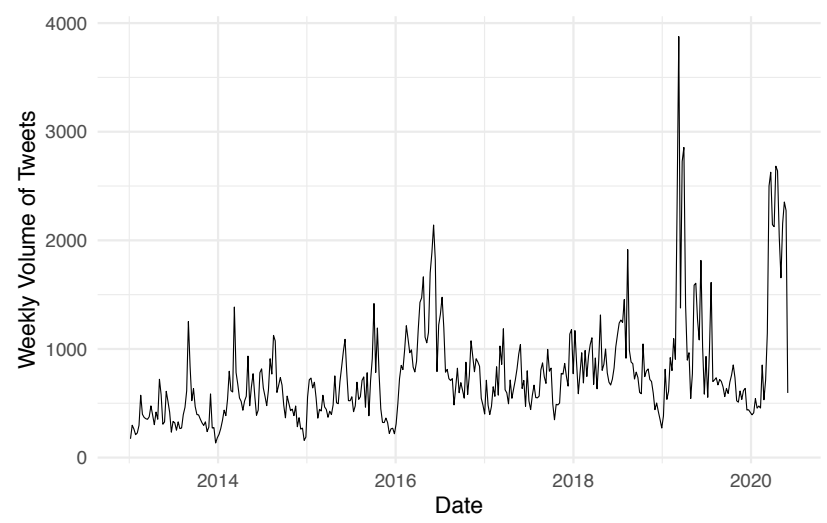

\section{Harsh Criticism}

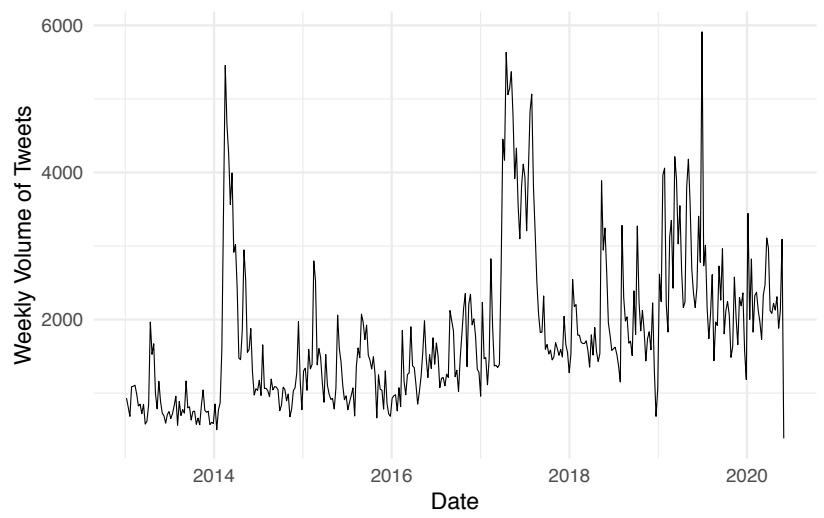


Figure A3: Mean Weekly Volume of Tweets Referencing Primary Topics

Foreign Policy

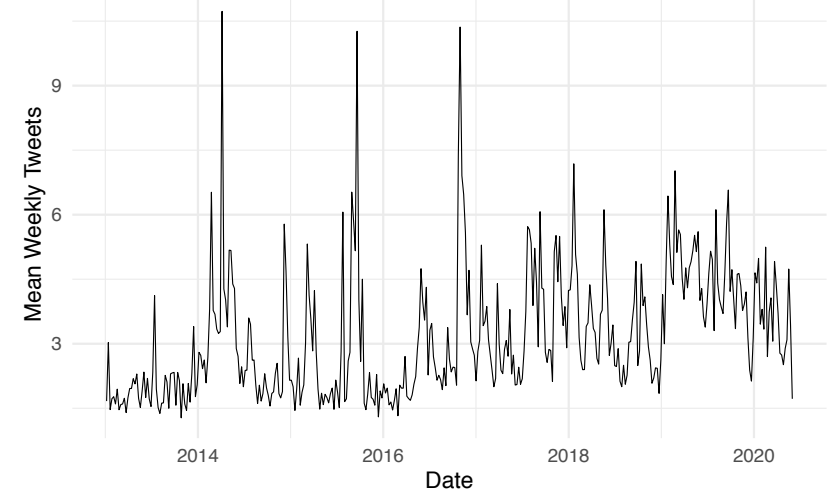

Protest

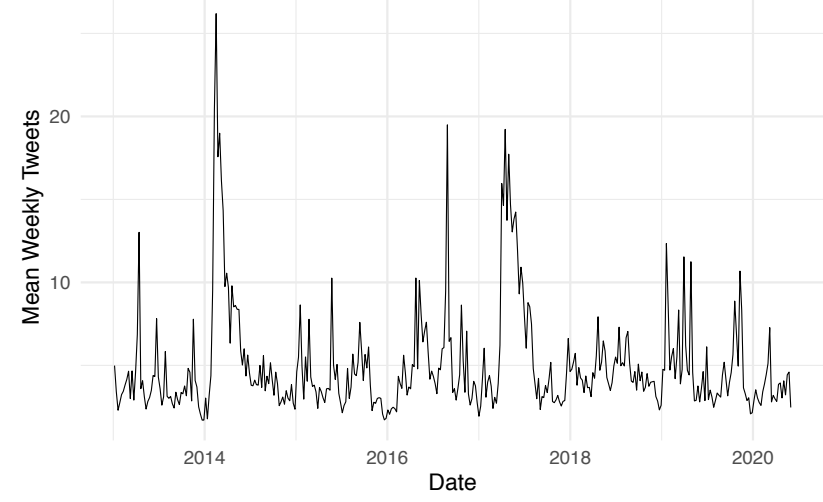

Service Provision

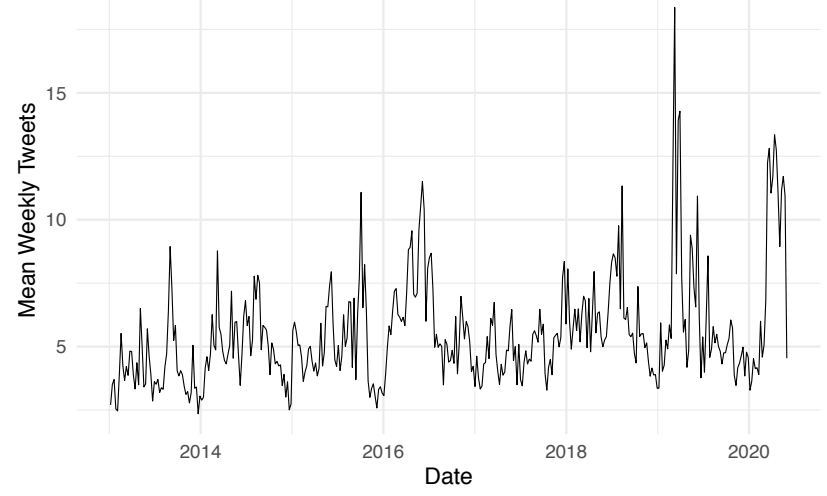

Harsh Criticism

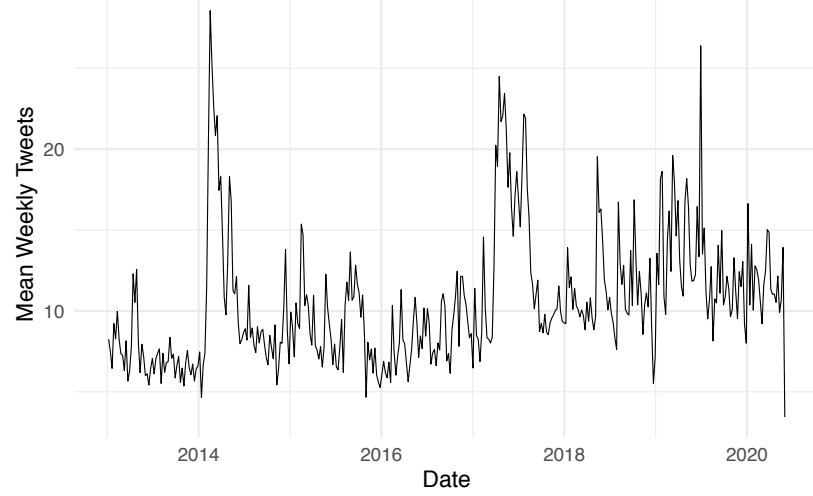


Figure A4: Weekly Proportion of Tweets Referencing Primary Topics

Foreign Policy

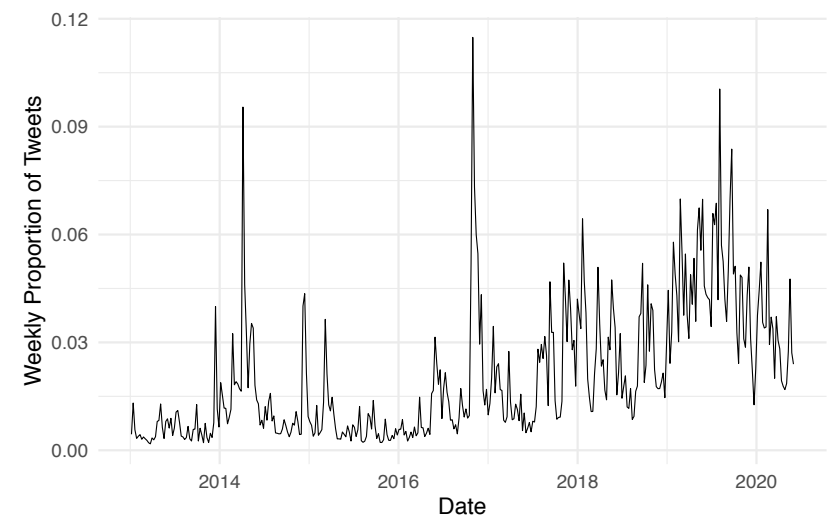

Protest

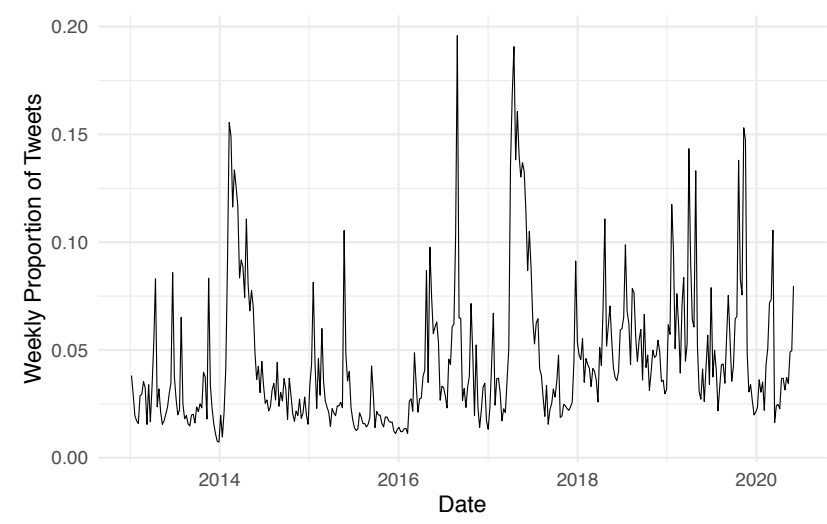

Service Provision

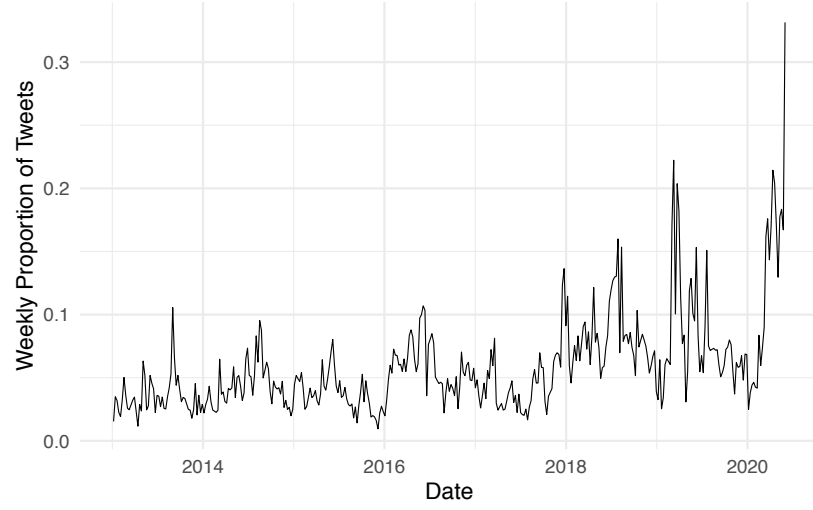

Harsh Criticism

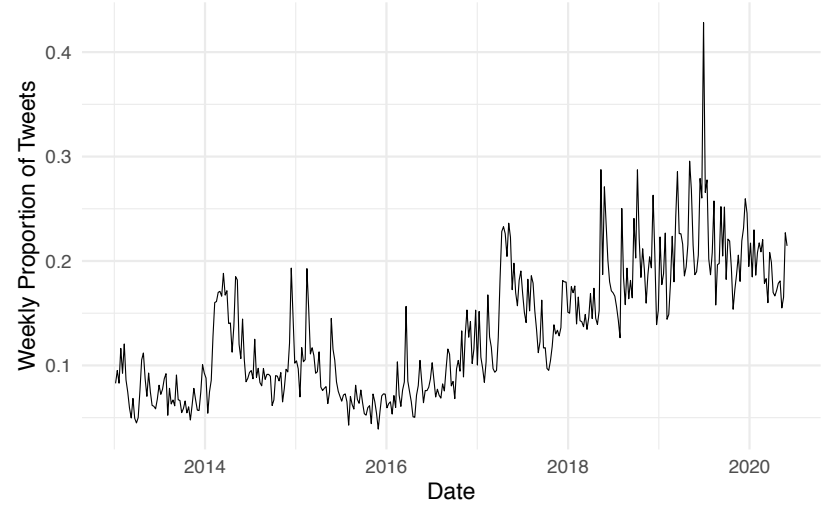

\section{A.3 Crowd-sourced Human Coding}

To create training data to classify tweets according to the position they expressed on economic sanctions or foreign intervention in Venezuela, we used Appen (formerly Figure8 / Crowdflower) a microtask platform to hire three native Spanish speakers to code each tweet. We coded 4000 tweets in total, 2000 with word2vec keywords indicating they referenced military intervention and 2000 with word2vec keywords indicating that they referenced economic sanctions. Intercoder reliability was high- $89 \%$ across all three coders on average. The English language instructions for the coders were as follows:

Overview: In this job, you will be presented with tweets on the topic of (economic sanctions/foreign intervention) in Venezuela. Review the tweets to determine the relevance to the subject and then answer a series of questions about each tweet.

Classification instructions:

- Read the tweet.

- Determine if the tweet is relevant to the topic. 
- If the tweet is relevant, answer the questions about the content of the tweet.

Question 1: Is this tweet related to (economic sanctions/foreign intervention)?

- Yes

- No

- Unclear

If yes:

Question 2: Does this tweet present (sanctions/foreign intervention) as a positive or negative policy option?

- Positive

- Negative

- Neutral

- Unclear

Positive: (Sanctions) Tweets that support the use or discussion of economic sanctions. (Intervention) Tweets that support the use or discussion of foreign intervention, including military intervention, humanitarian intervention, or naval blockades.

Negative: Tweets that denounce or criticize the policies or impacts of (sanctions/foreign intervention).

Neutral: Tweets that describe (sanctions/foreign intervention) neither positively nor negatively, like news articles or announcements that do not take a stand about whether or not to use sanctions.

We then used this human coded data to first train two binary Naive Bayes classifiers to remove irrelevant tweets (relevant to military intervention vs. irrelevant and relevant to sanctions vs. irrelevant). We then trained four binary Naive Bayes classifiers on the relevant tweets (pro-military intervention or not, anti-military intervention or not, pro-sanctions or not, and anti-sanctions or not). The classifiers all had high levels of precision and balanced accuracy, ranging from 82-95\% across classifiers.

\section{A.4 Classified Military and Sanctions Tweets}

Figures A5 and A6 show the results for military intervention and economic sanctions for tweets classified as being relevant to those topics and mentioning them positively or negatively. Results demonstrate that our findings are driven largely by increased positive mentions, with little to no effect on negative references. 
Figure A5: Military Intervention

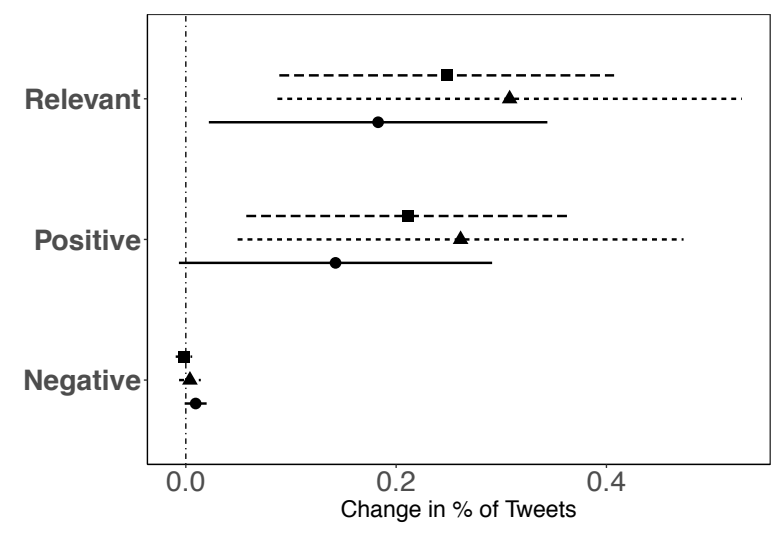

- Month FEs 4 Two-Way FEs $\$$ Time Trend
Figure A6: Sanctions

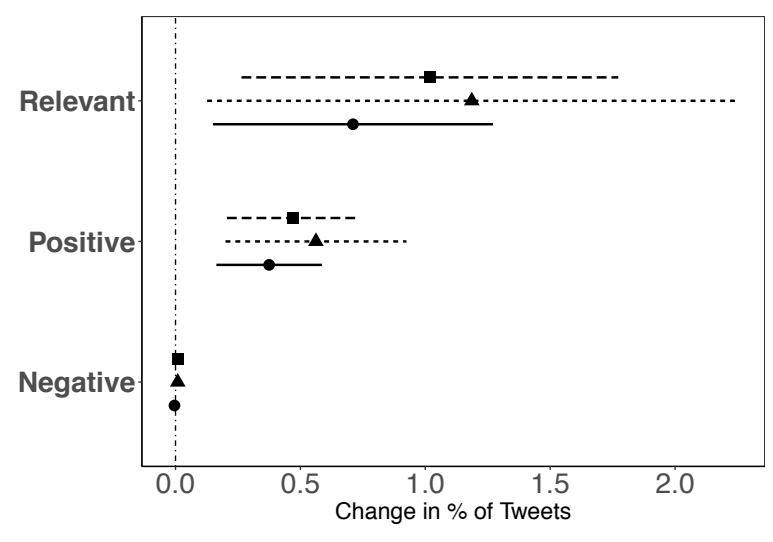

Month FEs $\uparrow$ Two-Way FEs $\uparrow$ Time Trend

\section{A.5 References to Exile}

References to exile itself increase in the months after leaving the country, providing greater confidence in the interpretation of findings.

Figure A7: Exile and Discussions of Exile
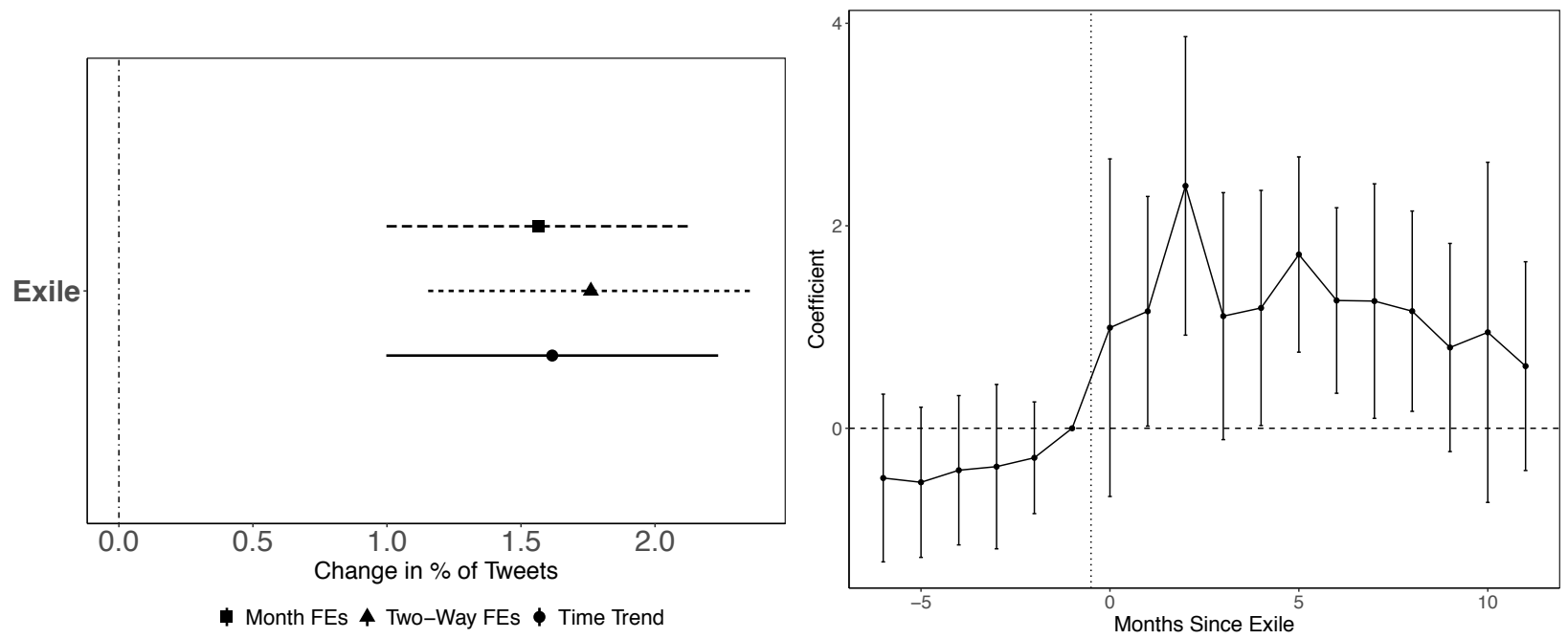

\section{A.6 Results by Location of Exile}

The below figures compares the effects for exiles in the US to exiles living elsewhere. There is no statistically detectable difference between the groups, which may be due to the sample being statistically underpowered when split, or be reflective of unity among the opposition abroad. Results are similar, but not shown, comparing exiles in Colombia to those elsewhere. 
Figure A8: US Compared to Other Exiles

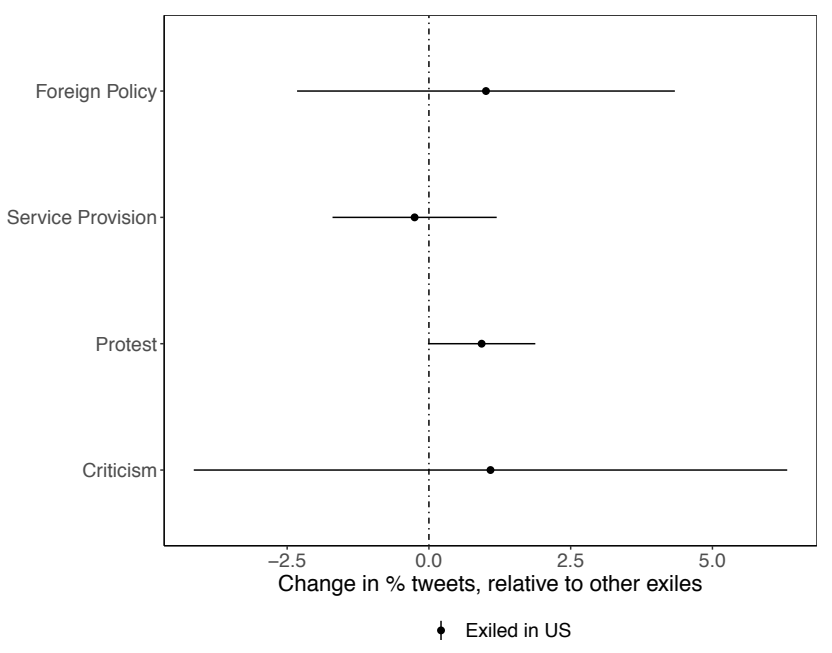

\section{A.7 T-Test Results}

T-test results demonstrate that our results hold even in a simple descriptive setup. Our data include all tweets in our sample; we show the difference in the percent of tweets mentioning a topic in the 30,60, or 120 days before and after an exile leaves Venezuela.

Figure A9: Pre-Post T-Tests

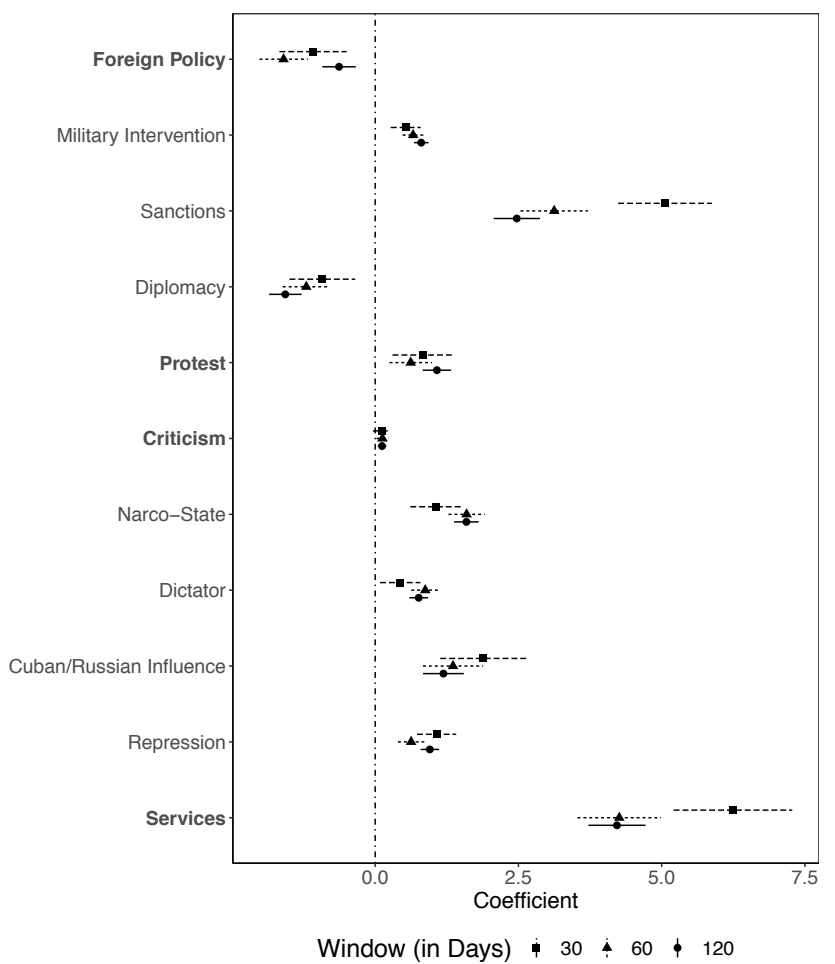




\section{Appendix B: Robustness Checks}

\section{B.1 Including Inactive Months}

In our main specifications, we do not include months where a Twitter account was dormant (e.g., where an activist did not tweet at all). Though we control for the number of tweets, the central purpose of this is to avoid conflating months where an elite did not tweet at all with those months where an elite did not tweet on a certain topic at all. Here we show that, with the exception of our results on protest, findings hold when using this alternative construction. Our findings on collective action thus remain weaker and more suspect than other results, though its robustness to other specifications does offer some reassurance.

Figure B1: Including Months with No Tweets

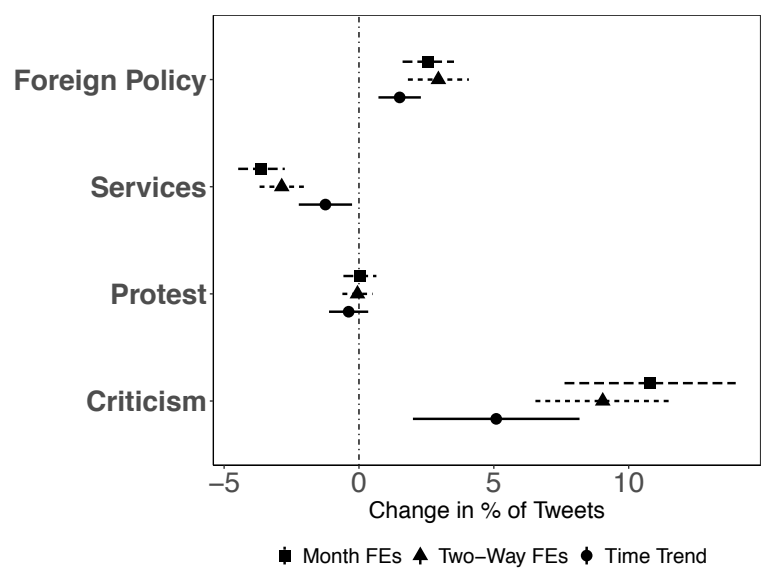

\section{B.2 Changing Event Study Estimation}

The event study design in the paper compares exiles before and after leaving, and thus does not incorporate those activists who did not go into exile. We can alternatively estimate the event study by including all in-country activist-months in the base period $(-1)$. Results are substantively unchanged.

Figure B2: Foreign Policy

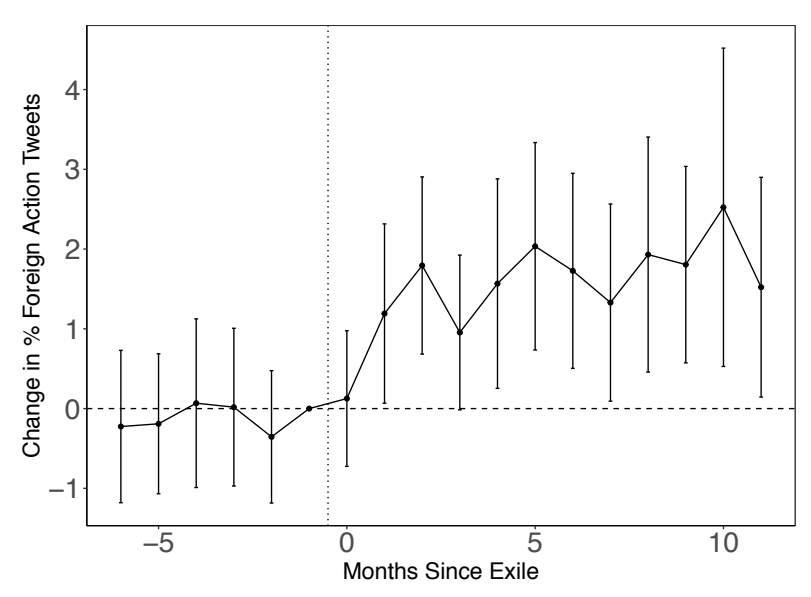

Figure B3: Services

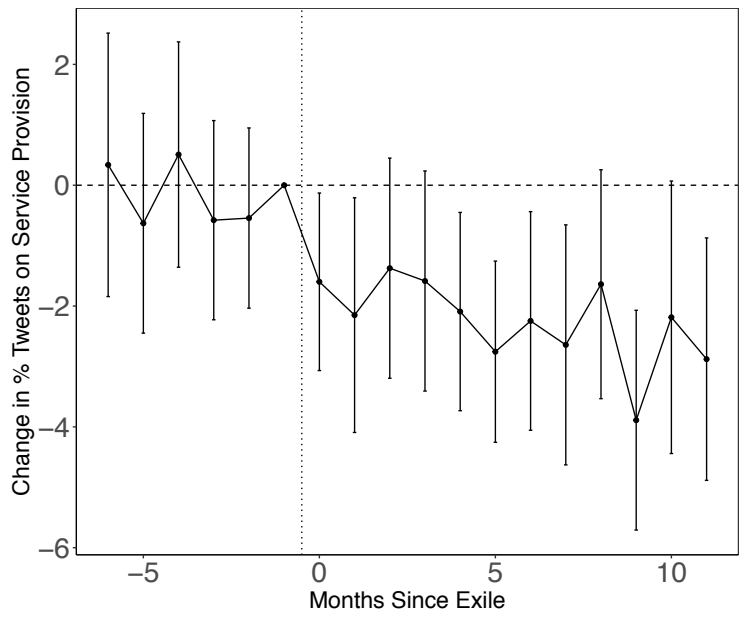


Figure B4: Protest

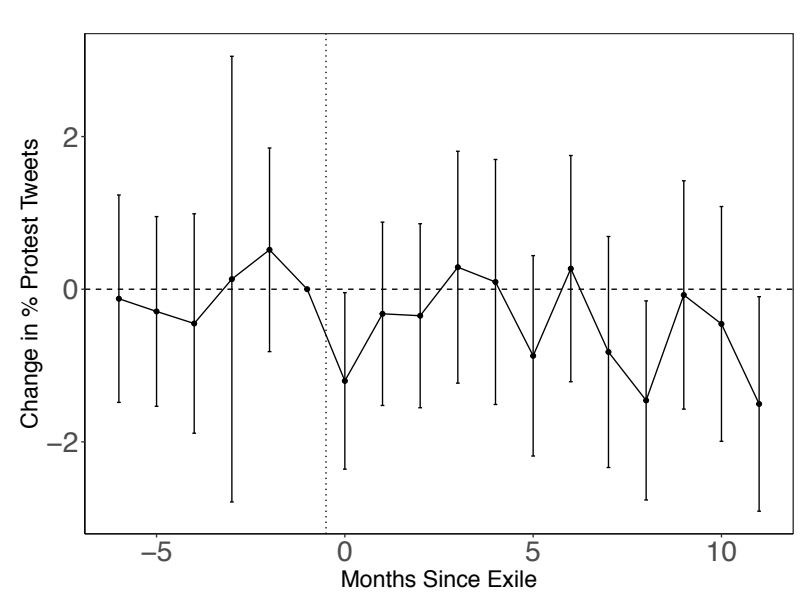

Figure B5: Harsh Criticism

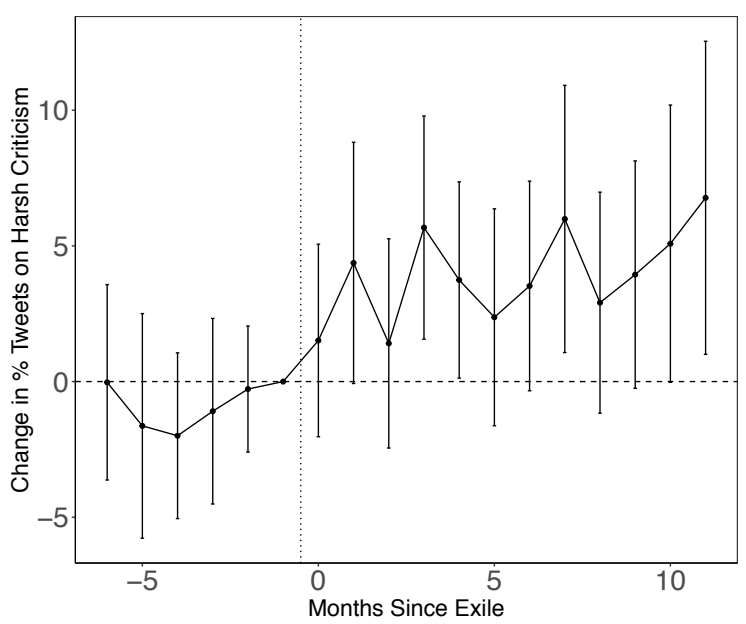

\section{B.3 Including Only Politicians}

Our sample is non-exhaustive. In order to reduce any concerns that this may be driving our results, we show in Figures B6 and B7 that findings hold when restricting our analysis to the most complete set of activists - politicians elected to the National Assembly or as mayors in the last two election cycles. We additionally show our findings hold when using on politicians elected in 2011 or after, in case those elected earlier behave fundamentally different online.

Figure B6: Politicians Only

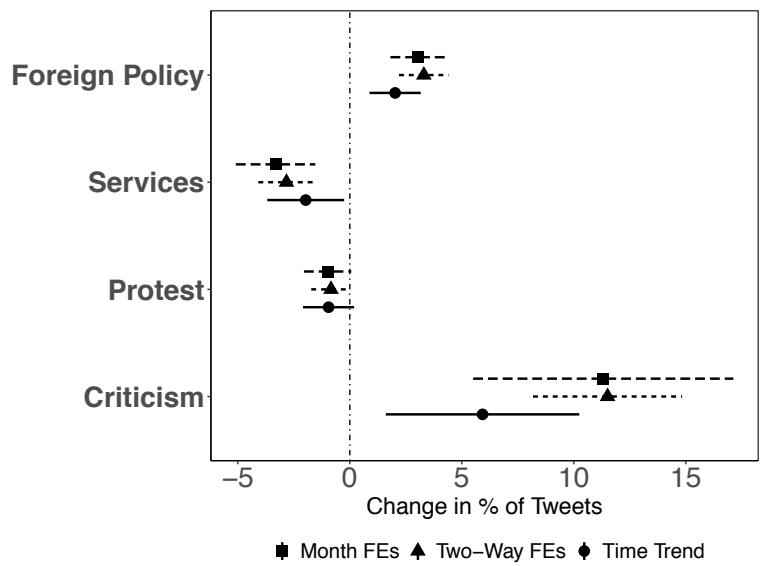

Figure B7: Politicians Elected after 2010 Only

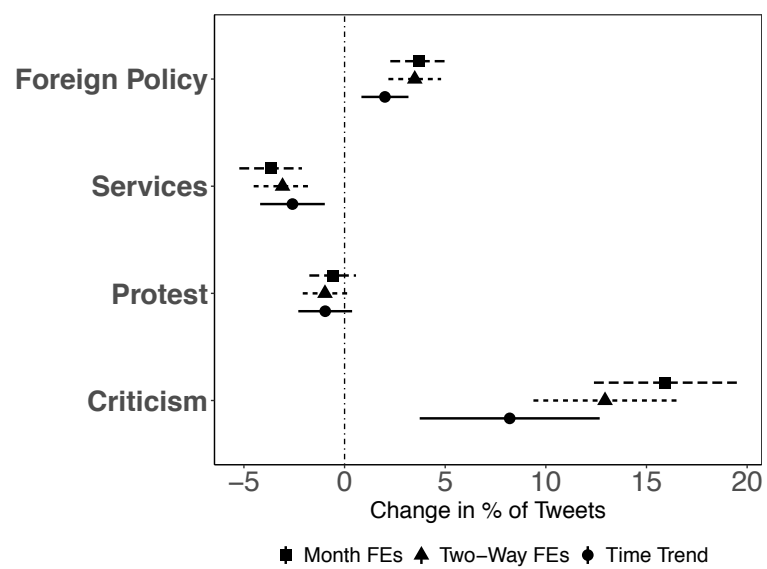

\section{B.4 Political Prisoners}

Maduro also uses detention of opponents to limit opposition. In case these periods of imprisonment precede exile, explaining results, we show here that findings hold when dropping those opponents who also served time in prison during the period of our sample B8 and when controlling for periods of imprisonment B9. 
Figure B8: Excluding Political Prisoners

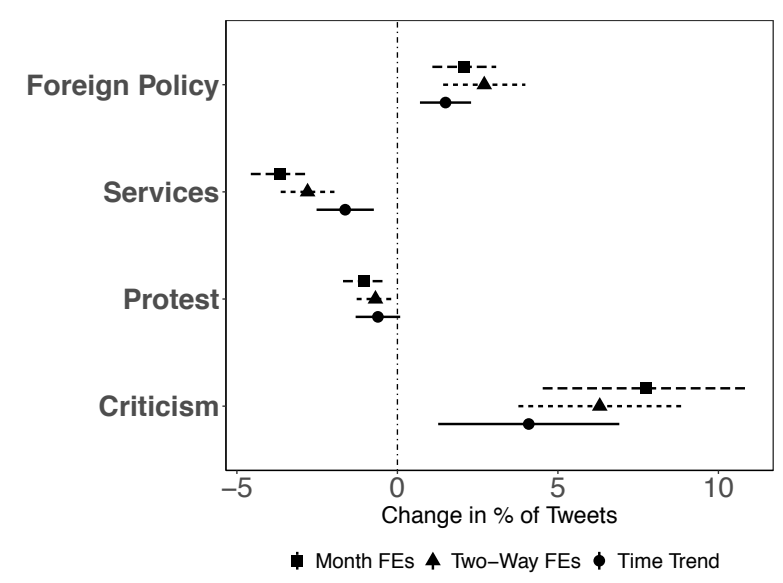

Figure B9: Controlling for Imprisonment

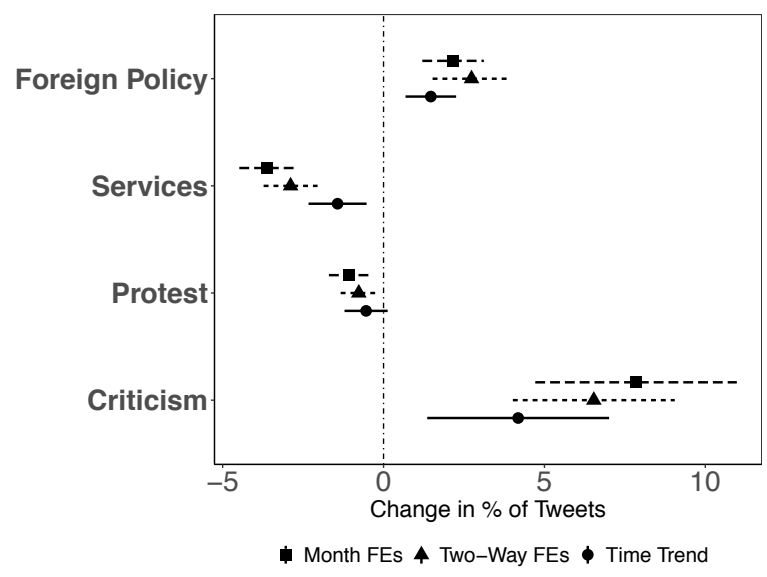

\section{B.5 Political Party}

Opposition parties in Venezuela range hardline to open to negotiating with the Maduro regime; because of this, members of the opposition likely differ both in preferences and in their likelihood of being exiled. To account for this, we show results controlling for party ID interacted with a time trend, and showing results only for Guaidós Voluntad Popular (VP). Results largely hold, though the findings on protest become noisier, particularly when subsetting to only VP.

Figure B10: Controlling for party ID

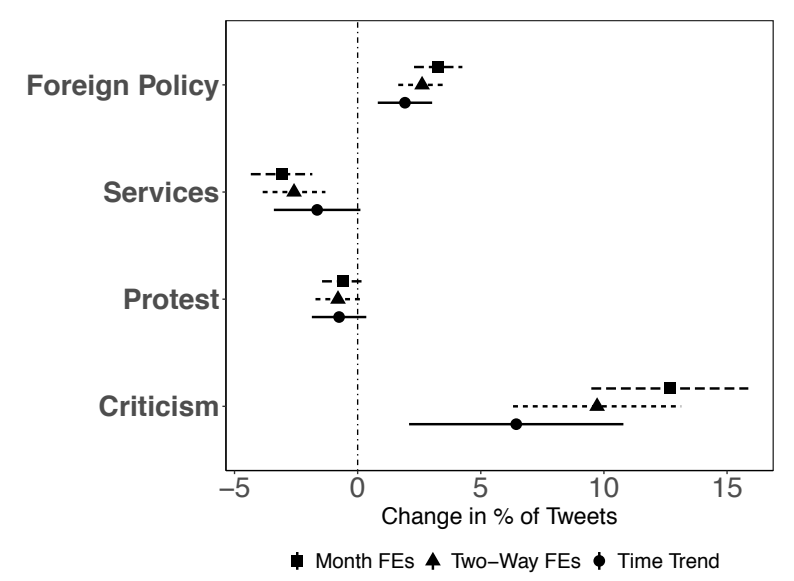

Figure B11: Including only VP

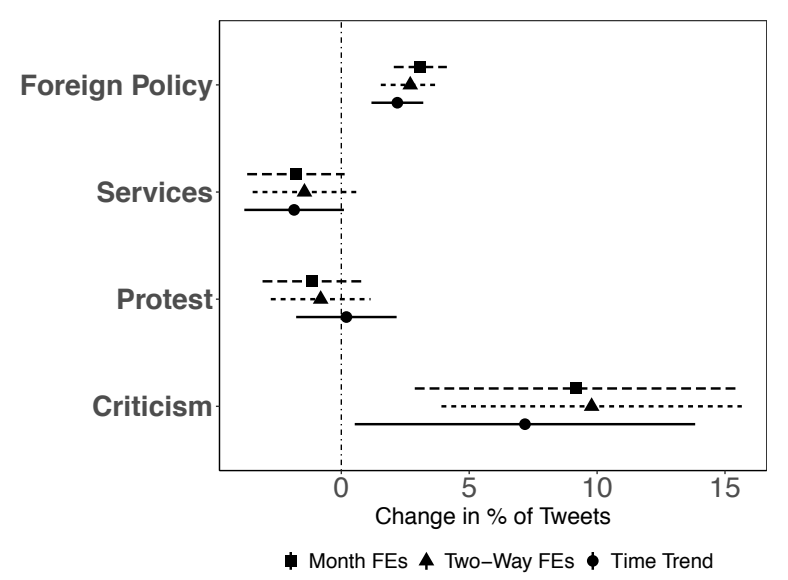

\section{B.6 Robustness to Dropping Individuals}

The following show that our results are consistent when dropping each individual user in turn. This provides greater confidence that results are not being driven by a small number of cases having disproportionate influence on findings. Figures below show the estimates for the model with one activist dropped, with confidence intervals in gray. 
Figure B12: Foreign Policy

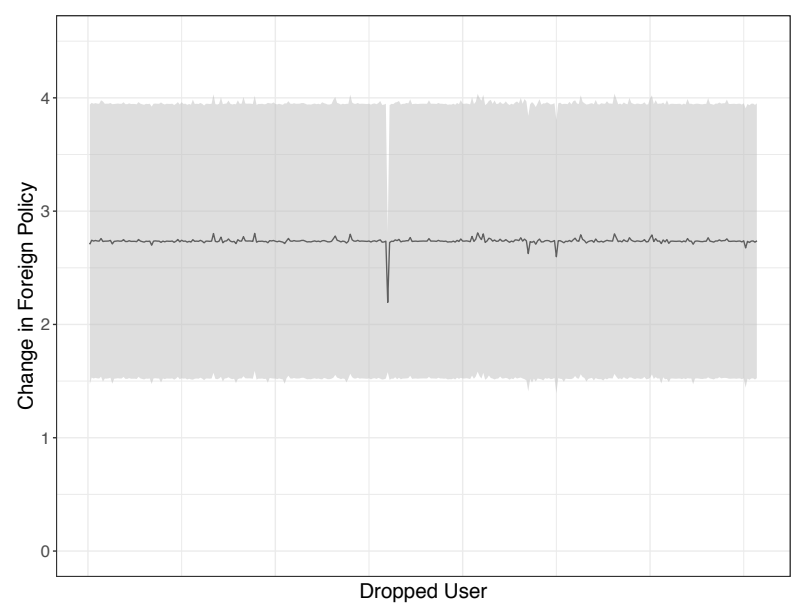

Figure B14: Protest

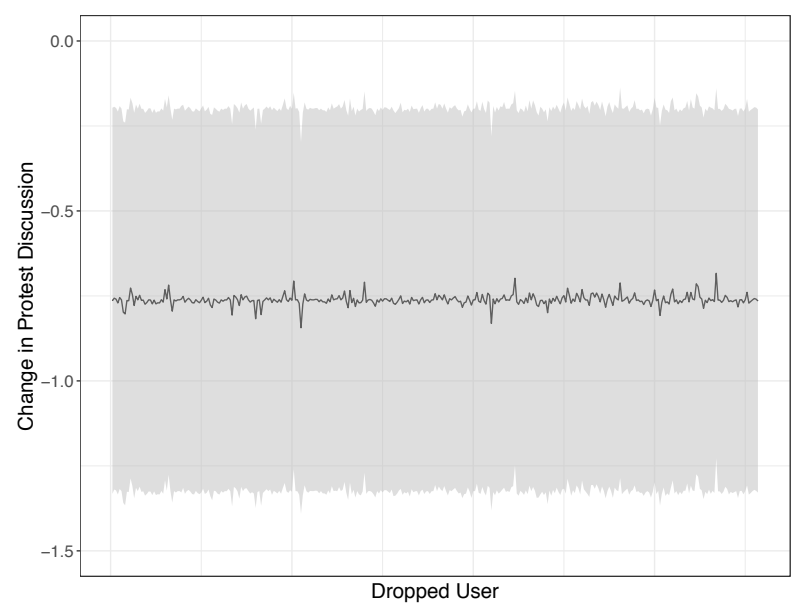

Figure B13: Service Provision

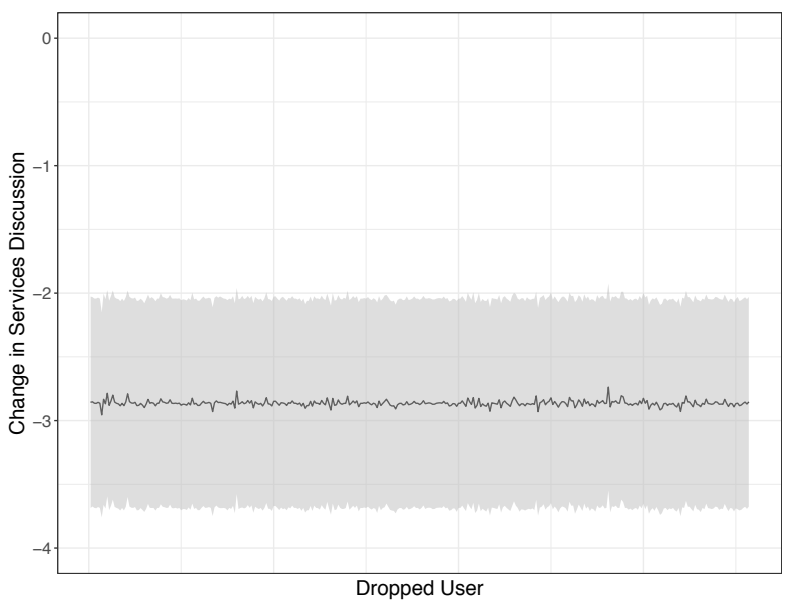

Figure B15: Harsh Criticism

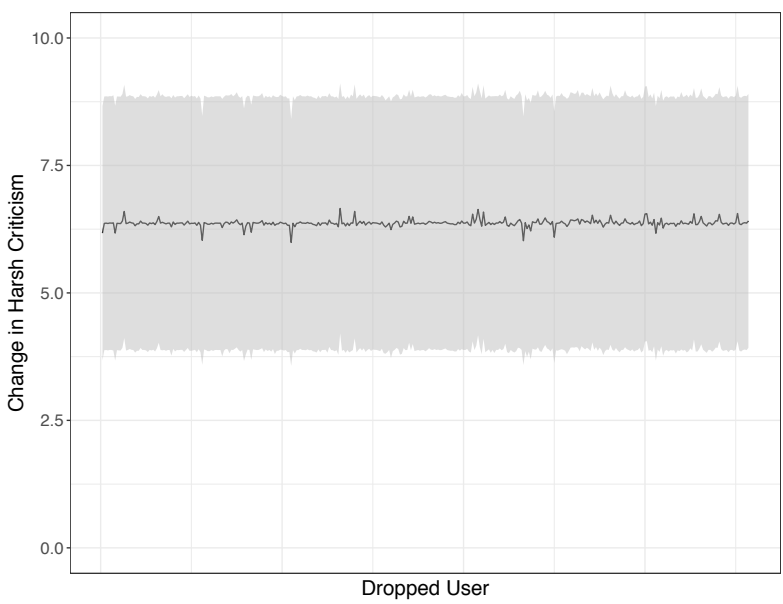

\section{B.7 Bacon-Goodman Decomposition}

Recent research has also raised concerns about the causal interpretation of two-way fixed effects difference-in-differences designs with staggered treatment timing when effects are heterogenous across time (which is often likely to be the case) (Bacon-Goodman; Imai and Kim). The central concern is that negative weights may be assigned when treatment effects and timing vary because already-treated units may serve as control groups. This is of somewhat less concern in our design because our sample of never-treated individuals is large, but we nonetheless conduct Bacon-Goodman decomposition for each of our four main outcomes. We show here that our estimates are similar regardless of the timing of treatment, and weights are similar across treatment periods.

\section{B.8 Callaway and Sant'Anna}

In this section, we show results using the Callaway and Sant'Anna DD estimator, which can be used to address concerns of bias in difference in differences designs with staggered treatment timing. Figure B18 shows the summary results for each dependent variable, while Figures B19 to B22 show event studies. Results are robust to using this alternative estimator, 
Figure B16: Bacon-Goodman Decomposition Plots

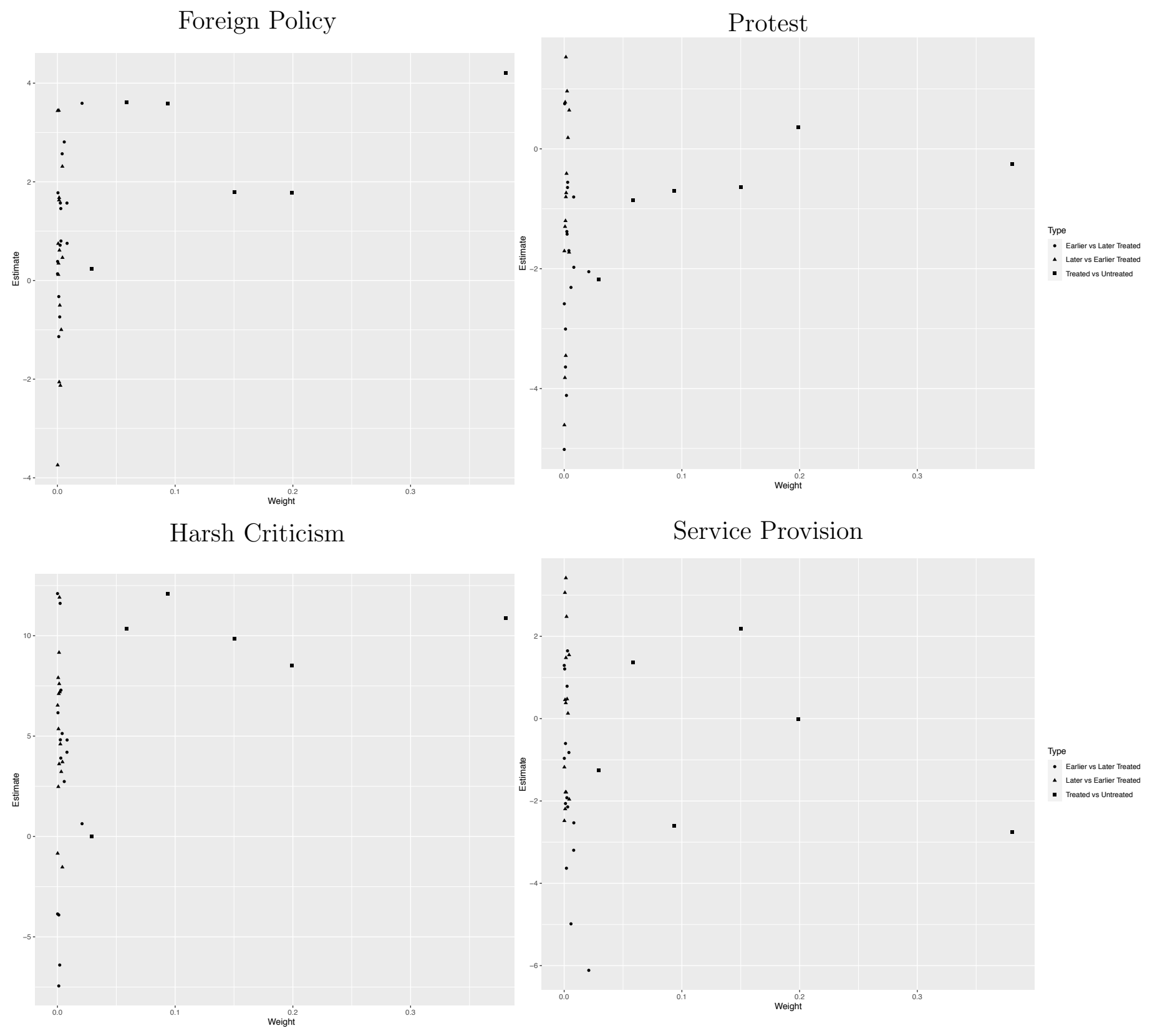


Figure B17: Bacon-Goodman Decomposition Tables

Foreign Policy

\begin{tabular}{|cccc}
\hline Type & $\begin{array}{c}\text { Average } \\
\text { Estimate }\end{array}$ & $\begin{array}{c}\text { Number of 2x2 } \\
\text { Comparisons }\end{array}$ & $\begin{array}{c}\text { Total } \\
\text { Weight }\end{array}$ \\
\hline $\begin{array}{c}\text { Earlier vs Later } \\
\text { Treated }\end{array}$ & 1.06 & 15 & 0.06 \\
\hline $\begin{array}{c}\text { Later vs Earlier } \\
\text { Treated }\end{array}$ & 0.36 & 15 & 0.03 \\
\hline $\begin{array}{l}\text { Treated vs } \\
\text { Untreated }\end{array}$ & 2.54 & 6 & 0.91 \\
& & \\
\end{tabular}

Harsh Criticism

\begin{tabular}{|cccc|}
\hline Type & $\begin{array}{c}\text { Average } \\
\text { Estimate }\end{array}$ & $\begin{array}{c}\text { Number of 2x2 } \\
\text { Comparisons }\end{array}$ & $\begin{array}{c}\text { Total } \\
\text { Weight }\end{array}$ \\
\hline $\begin{array}{c}\text { Earlier vs Later } \\
\text { Treated }\end{array}$ & 2.79 & 15 & 0.06 \\
\hline $\begin{array}{c}\text { Later vs Earlier } \\
\text { Treated }\end{array}$ & 5.20 & 15 & 0.03 \\
\hline $\begin{array}{c}\text { Treated vs } \\
\text { Untreated }\end{array}$ & 8.62 & 6 & 0.91 \\
\hline
\end{tabular}

\section{Protest}

\begin{tabular}{|cccc|}
\hline Type & $\begin{array}{c}\text { Average } \\
\text { Estimate }\end{array}$ & $\begin{array}{c}\text { Number of 2x2 } \\
\text { Comparisons }\end{array}$ & $\begin{array}{c}\text { Total } \\
\text { Weight }\end{array}$ \\
\hline $\begin{array}{c}\text { Earlier vs Later } \\
\text { Treated }\end{array}$ & -2.03 & 15 & 0.06 \\
\hline $\begin{array}{c}\text { Later vs Earlier } \\
\text { Treated }\end{array}$ & -1.04 & 15 & 0.03 \\
\hline $\begin{array}{c}\text { Treated vs } \\
\text { Untreated }\end{array}$ & -0.71 & 6 & 0.91 \\
\hline
\end{tabular}

Service Provision

\begin{tabular}{cccc}
\hline Type & $\begin{array}{c}\text { Average } \\
\text { Estimate }\end{array}$ & $\begin{array}{c}\text { Number of 2x2 } \\
\text { Comparisons }\end{array}$ & $\begin{array}{c}\text { Total } \\
\text { Weight }\end{array}$ \\
\hline $\begin{array}{c}\text { Earlier vs Later } \\
\text { Treated }\end{array}$ & -1.6027 & 15 & 0.0624 \\
\hline $\begin{array}{c}\text { Later vs Earlier } \\
\text { Treated }\end{array}$ & 0.1360 & 15 & 0.0260 \\
\hline $\begin{array}{c}\text { Treated vs } \\
\text { Untreated }\end{array}$ & -0.5116 & 6 & 0.9116 \\
\hline
\end{tabular}


except for harsh criticism, which is substantively stable but is not statistically significant. Breaking the data down by time shows that results are stronger for the period 2016 and after. Our descriptive results in Appendix A suggest that this may be due to these criticisms becoming more salient as Maduro consolidates power.

Figure B18: Callaway and Sant'Anna estimator

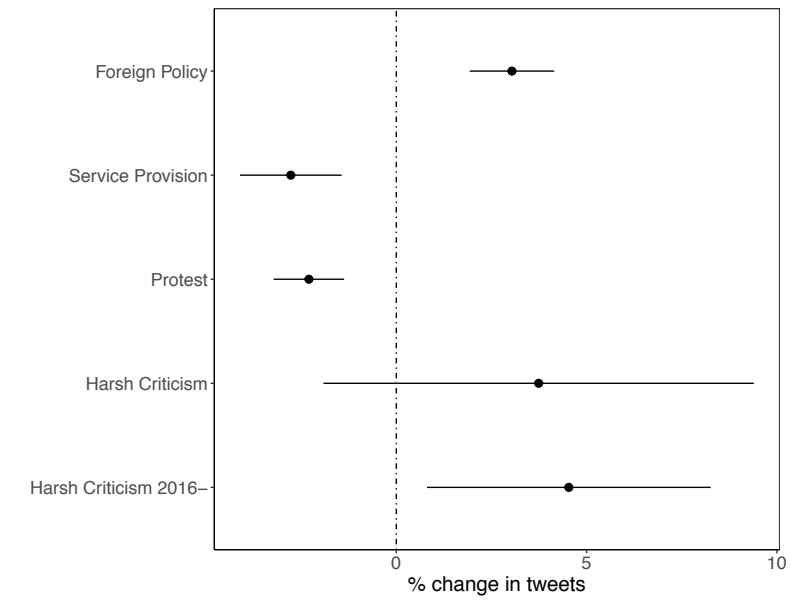

Figure B19: Foreign Policy

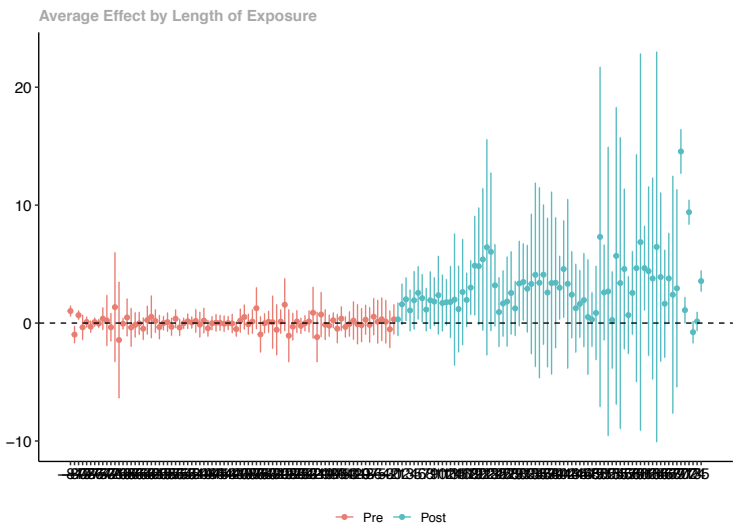

Figure B21: Protest

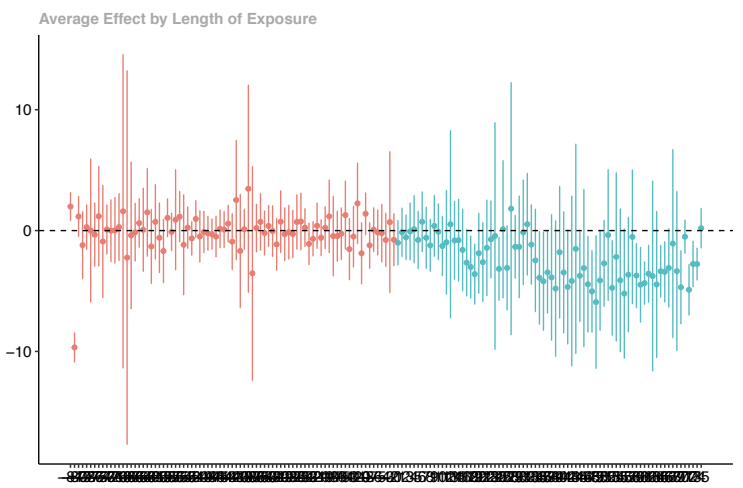

$\rightarrow$ Pre $\rightarrow$ Post
Figure B20: Service Provision

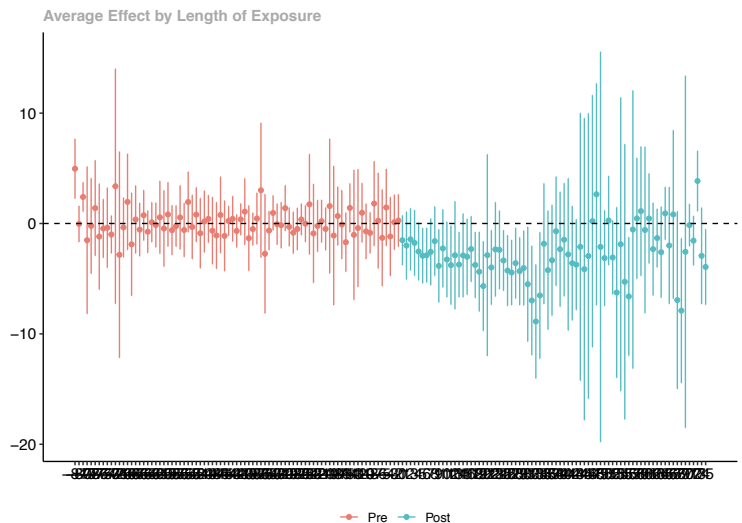

Figure B22: Harsh Criticism

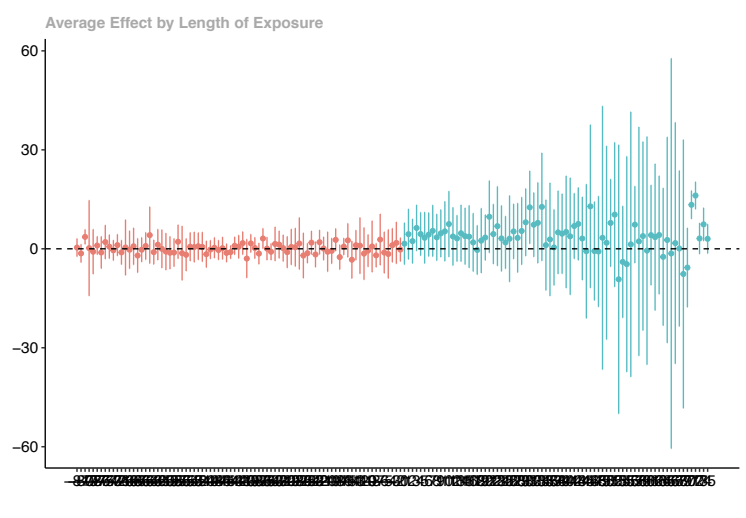

$\rightarrow$ Pre $\rightarrow$ Post 
Figure B23: Harsh Criticism 2016-

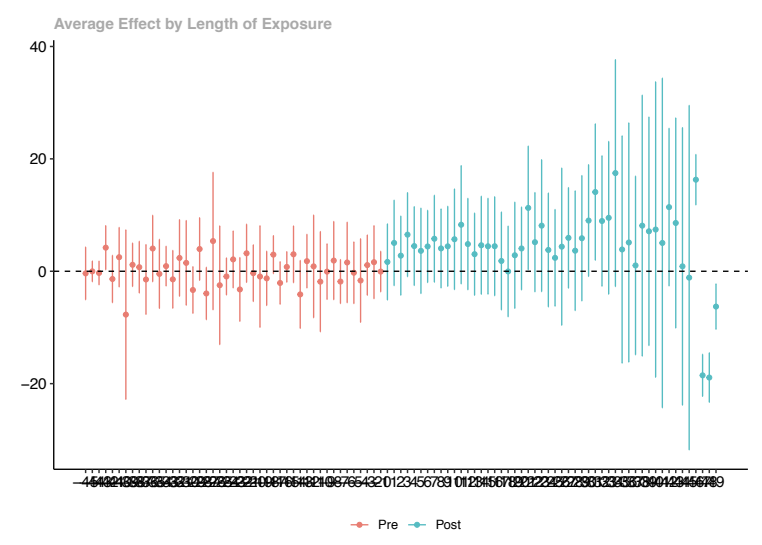

\section{B.9 Removing Early Exiles}

Concerns about the causal interpretation of two-way fixed effects models with staggered treatment timing are driven primarily by the use of earlier treated units as a comparison group for later treated units. While the nature of our sample, which includes many nevertreated individuals, reduces these concerns somewhat, we additionally show our results hold when excluding those individuals exiled prior to the beginning of our Twitter data and including only those exiled later in the regime (Figures B24 and B25).

Figure B24: Excluding Early Exiles (pre-2013)

Figure B25: Only Late Exiles (post-2017)
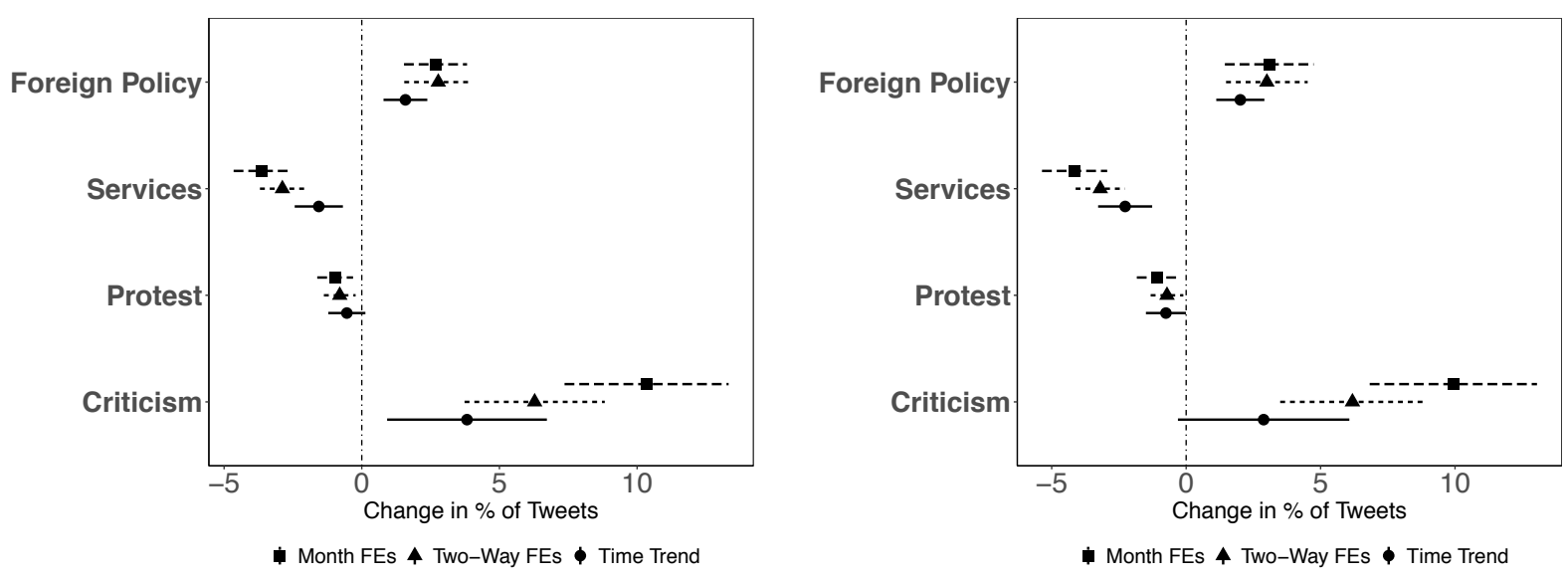